\title{
¿Hacia un humanismo trans-antropocéntrico? Peter Singer y los "derechos" de los animales
}

\section{1. ¿Una nueva ética para un nuevo paradigma cosmovisional?}

El avance progresivo de los diferentes saberes, tanto científicos como filosóficos, acerca del ser humano y del universo, nos está llevando a replantear, a ampliar y a completar muchos aspectos del mundo de la ética y de sus fundamentos. Hasta hace no mucho tiempo, se pensaba que la ética abarcaba el ámbito de lo puramente humano, tanto en su dimensión individual como social. Pero, en la actualidad, esos avances científicos están obligando al ser humano a tener en cuenta dentro de sus obligaciones éticas otros muchos aspectos que hasta este momento no los había tenido en cuenta, entre ellos, todo el entorno de la biosfera.

Son tres las principales áreas que parecen exigir de la reflexión ética una especial atención:

a) En el ámbito social, el fenómeno de la globalización o de la mundialización (con todas las ambigüedades y pluralidad de lecturas que merece) nos está obligando cada vez más a entendernos los seres humanos como una macrosociedad - que supera las simples relaciones nacionales y plurinacionales-, para vernos como una única sociedad interrelacionada, en la que todos somos ya casi directamente responsables de todos. Se impone, por tanto, pro-

¿Hacla un humanlsmo trans-antropocénifleo? 
yectar una nueva ética mundial que regule esta realidad y que establezca un diálogo entre culturas y entre religiones'.

b) En el ámbito de la biología y de la genética, los avances en cl descilramiento del genoma humano y el alcance de las posibilidades de la fecundación asistida, así como de la ingeniería genética, nos han hecho vislumbrar todo el inmenso campo de la biotecnología, que, por sus importantísimas consecuencias para el futuro de nuestra especie, están dando lugar a nuevos afrontamientos éticos de estos problemas también nuevos (bioética), campo lleno de enormes dificultades y peligrosas consecuencias, así como de espléndidas realizaciones y promesas².

c) Y en el ámbito ecológico, fenómenos como la superpoblación, los avances de la tecno-industria y el progresivo deterioro del medio ambiente, nos han ido descubriendo la posibilidad de que el fuerte y progresivo impacto de nuestra especie sobre el planeta en que vivimos, puedan llevar aparejadas tan fatales consecuencias que pueda incluso suponer la desaparición de nuestra especie, y hasta de todo el planeta. Esto supone un nuevo ámbito de responsabilidad de la que hasta hace no muchas décadas no se era consciente, responsabilidad que no sólo se extiende a la generación humana contemporánea, sino, sobre todo, a las generaciones futuras. De ahí que nos hallemos en plena eclosión de éticas ecológicas ${ }^{3}$, con ámbitos éticos complementarios, como el ecofeminismo, la ecoteología, etc. ${ }^{4}$.

I. Cfr. H. Küng, Proyecto de una ética mundial, Madrid, Trotta, 1991; H. Küng y K.-J. Kuschel (eds.), Hacia una ética mundial. Declaración del parlamento de las religiones del mundo, Madrid, Trotta, 1994: Leonardo Boff. Nueva Era: La civilización planetaria, Estella, Verbo Divino, 1995; Hans Jonas, El principio responsabilidad. Ensavo de una ética para la civilización tecnológica, Barcelona, Herder, 1995.

2. Cf́r. Diego Gracia, Fundamentos de bioética, Madrid, Eudema. 1989; Id., Introducción a la bioética. Bogotá, 1991; Id., Procedimientos de decisión en ética médica, Madrid, 1991; Javier Gafo, Problemas éticos de la manipulación genética. Madrid, Edic. Paulinas, 1992; T.L. Beauchamp-J.F. Childress, Principles of biomedical ethics, Nueva York, 1979; T.L. Beauchamp-L.B. McCullough, Ética médica. Las responsabilidades morales de los médicos, Barcelona, 1987; J. Gafo (Ed.), Dilemas éticos de la medicina actual, 5 vols., Madrid. 1986-1991; B. Häring, Moral y medicina, Madrid, 1973; G.H. Kieffer, Bioética, Madrid, 1983; R. Martín Mateo, Bioética y derecho, Barcelona, 1987; B. Sporken, Medicina y ética en discusión, Estella, 1974; A.C. Varga, Bioética, Bogotá, 1988; M. Vidal. Bioética, Madrid, 1989.

3. La bibliografía sobre ética ecológica es ya inabarcable y de muy diversas tendencias. Indicamos sólo algunos textos de interés: E. Ashby. Reconciliar al hombre con el ambiente, Madrid, 1981; W. Dobben-R. Lowe-McConnell (eds.), Conceptos unificadores de ecologia, Madrid, 1980; F. González Bernáldez, Invitación a la ecología humana. La adaptación afectiva al entorno, Madrid, 1985; R. Hernández del Aguila, La crisis ecológica, Barcelona, 1985; J. Pasmore. La responsabilidad del hombre frente a la naturaleza, Madrid, 1978; X. Pikaza y otros, El desafio ecológico, Salamanca, 1985; N.M. Sosa, Ética y ciencia: la responsabilidad moral del científico, CuRealSoc, 23-24 (1984), 5-20; Id., Ética ecológica: necesidad, posibilidad, justificación y debate. Madrid, 1990; E. Goldsmith, El Tao de la ecologia, Barcelona, Icaria, 1999.

4. Cfir. Teologia, Ecología y Desarrollo Sostenible, número monográfico de Cristianismo y Sociedad, 1999, No 140-141; VV.AA.. Ecología y creación. Fe cristiana y 
Aunque estos tres ámbitos están íntimamente correlacionados, y no pueden tratarse de forma totalmente aislada, cada uno de ellos genera su propia problemática y exige soluciones específicas. No es mi interés tratar y reflexionar aquí sobre todos ellos; me interesa ahora solamente el tercero, aunque a lo largo de las reflexiones tendremos que hacer referencia a algunos aspectos de los otros dos ámbitos.

El avance de las ciencias biológicas y el fuerte impacto que la tecno-industria está ejerciendo sobre el entorno ecológico', nos ha ido mostrando que nuestra relación con el ambiente era profundamente miope e insuficiente. La Tierra y todas las especies vivas que en ella habitan forman una unidad viva, profundamente interrelacionada. La conformación de dicha unidad se ha dado a través de un equilibrio ecológico sabiamente construido a lo largo del proceso evolutivo. Ello ha motivado a que algunos científicos lleguen a considerar a nuestro planeta como un ser vivo: Gaia ${ }^{6}$. Aunque no necesitemos seguir estas tesis ecologistas, no cabe duda que la ética humana tiene que pasar, de entenderse solamente dentro del ámbito de las relaciones interhumanas ("contrato social"), a entenderse dentro de la óptica de un "contrato natural", en el que entren también las relaciones del ser humano con el entorno ecológico ${ }^{7}$. Es decir, toda esta nueva situación de deterioro ecológico nos habría llevado a darnos cuenta de que existe también una cierta relación moral con la naturaleza, lo que estaría produciendo, de rebote, una nueva imagen del ser humano y de las relaciones con su entorno ecológico.

Dentro de esta nueva e influyente sensibilidad ecológica, pero autónoma de ella ( $y$ en muchas ocasiones con relaciones no muy pacíficas), está haciéndose presente en los medios académicos y de comunicación del mundo entero (comenzando por el mundo anglosajón, pero extendiéndose por el primer mundo) una corriente filosófica y ética en defensa de los derechos de los animales.

Esta nueva sensibilidad es muy amplia y abarca posturas muy diversas, desde quienes extienden tales derechos a todos los animales sin distinción, —-defendiendo, en consecuencia, el vegetarianismo como único modo ético de alimentación humana-, hasta quienes restringen la aplicación de derechos humanos sólo a los animales superiores, como a los mamíferos, o incluso sólo a los simios ${ }^{x}$.

defensa del Planeta, Salamanca, Universidad Pontif. de Salamanca, 1991; Juan Noemi C., Mysterium cretionis. Sobre la posibilidad de una aproximación a la realidad en cuanto creación de Dios (1). Teología y Vida, XL (1999), 372-399; Leonardo Boff, Religión, justicia societaria y reencantamiento de la creación, Pasos (Costa Rica), 1993, No 45, 1-10; Y. Hedström, Hacer ecoteología, Pasos, 1986, № 4, 11-16; Roy H. May, Apuntes para una teología de la tierra, Pasos, 1996, № 63, 24-32.

5. Cfr. A. Dou (ed.), Aspectos éticos del desarrollo tecnológico, Bilbao, Mensajero, 1979.

6. Cfr. J. Lovelock, Gaia. A new Look at Life on Earth, Oxford, 1979 (trad. cast. : Madrid, 1983).

7. Cfr. M. Serres, El contrato natural, Valencia, Pre-Textos, 1991.

8. Cfr. el número monográfico de Teorema, vol. XVIII/3 (1999), dedicado al tema de "los derechos de los animales". 
Acjuí nos vamos a detener en esta postura más restringida, sin detrimento de hacer lugaces referencias a las otras posturas defensoras de los supuestos "derechos" de los animales.

\section{El descubrimiento de los “derechos de los animales".}

La apelación a los Ilamados "derechos de los animales" viene de lejos; no es un lenómeno reciente. Se suele hacer referencia, como autor clave, al filósofo utilitarista inglés J. Bentham (1748-1832)". Ahora bien, la referencia a los animalcs expresando algún tipo de sensibilidad hacia lo que en nuestra época se están denominando "derechos de los animales", viene de bastante antes. Puede verse en el libro de J. Mosterín y Jorge Riechmann, Animales y ciudadanos", una amplia selección de textos de fillósolos importantes que, desde Descartes hasta nuestros días, han presentado alguna reflexión acerca del cstatuto de los animales respecio a los seres humanos.

\subsection{La obra de Peter Singer.}

Pero la ligura clave que en la aclualidad ha dado nuevo impulso a este tema y lo ha hecho popular es el filósofo australiano Peter Singer. Sus libros están icniendo un fucrte impacto en la opinión pública, por lo novedoso de su postura, por la seriedad y profundidad con que la defiende, así como la claridad y valenlía con cyuc expone sus argumentos. La carrera militante de Singer ha recorrido diversas lases o vicisitudes. Comenzó su trayectoria formando parte de los movimientos contra la guerra del Vietnam, publicando sobre ello su primer libro, Democracia y desobediencia", donde discute en qué casos y circunstancias se puede justificar la desobediencia civil.

En su siguiente libro, Liberación animal'2, convertido muy pronto en la auténtica biblia del movimiento en defensa de los animales, propone que el principio de igualdad entre los hombres hay que extenderlo a todos los animales sin distinción, aunque defiende especiales derechos para los animales más cercanos a la especie humana, los grandes simios.

Este texto lo completa con un libro posterior, escrito en colaboración con Paola Cavalieri, titulado El proyecto "gran simio". La igualdad más allá de la humanidad ${ }^{13}$. En este libro se recoge la "Declaración sobre los Grandes Simios",

9. Cfr. Gary L. Francione, El error de Bentham (y) el de Singer), Teorema, XVIII/3 (1999), 39-60.

10. Madrid, Talasa, 1995. Igualmente, cfr., M. Garrido, Apuntes para la historia de nuesIra visión moral de los animales, y C. García-Trevijano (comp.). Selección histórica de textos sobre el estatuto ético de los animales, ambos trabajos en Teorema, XVIII/3 (1999), pp. 151-155 y 157-192, respect.

11. Barcelona, Ariel, 1985.

12. Madrid, Trotta, 1999 (original inglés: 1975).

13. Madrid, Trotta, 1998. 
lïrmada y delendida, junto con los dos editores del libro, por importantes cientílicos neozclandeses y australianos, como J. Goodall, Adams, Nishida, Roger y Dehorah Fouts, Miles, Petlerson, Gordon. y otros. Esta Declaración, que fuc presentada como propuesta de ley al parlamento neozelandés, proponc extender la igualdad moral. presentc aunque no de forma completa dentro de la cspecie humana. a las especies animales más ccrcanas a los humanos, como son los grandes simios (chimpancé, gorila y orangután), reconociéndoles "el derecho a la vida, la protección de la libertad individual y la prohibición de la tortura”, exigiéndose cyue sus "intereses y dercchos deben ser salvaguardados por guardianes humanos del mismo modo cyue se hace con ciertos grupos humanos, como los niños y los débiles mentales"'14.

Pero Peter Singer no se ha limitado a teorizar y defender los derechos de los animales. sino que, en la medida en que los planteamientos sobre los derechos de los animales los basa en una nueva propuesta de delinición de "persona" y de distinción o separación entre la consideración élica del ser humano y las demás especies animales (sobre todo las de los grandes simios, como ha quedado dicho), considera que ha llegado en momento de replantear con nuevos parámetros todo el mundo de la ética. Así lo propone en Repensar la vida y la muerte (El derrumbe de muestra ética tradicional) ${ }^{\prime s}$. Para Singer, la desaparición de la barrera o distinción tradicional entre hombre y animales, obliga a redefinir el concepto de vida humana, con claras y rotundas repercusiones sobre la discusión ćlica acerca del aborto y de la eutanasia. Su estilo directo y claro a la hora de plantear estos problemas tan candentes en la aclualidad, hace que se lea con gran interés c incluzca al lector a pensar con atención sus planteamientos. Lo central de sus rellexiones es que no sólo nos jugamos en estos temas los problemas especílicos que surgen a la hora de delinir el origen y el fin de la vida humana, sino que en la resolución de esos problemas será elemento básico la postura que tengamos sobre el estatuto ontológico y ético de la persona humana (tanto en el caso del embrión como en el del moribundo).

En uno de sus últimos libros, Ethics into Action. Henry Spira and The Animal Liberation Movement: ${ }^{1 / 1}$, podríamos decir que da un paso más, en la medida en cue no se limita a teorizar sobre los derechos de los animales, sino que proponc estratcgias de acción encaminadas a extender estos planteamientos en la sociedad, y conseguir el logro concreto de estos supuestos derechos animales. Para cllo, nos presenta el ejemplo y las estrategias desarrolladas por su amigo y antiguo discípulo, Henry Spira, militante destacado de esta causa.

14. Lil provecto "gran simio", o.c., pp. 12-13.

15. Barcelona. Paidós, 1997. Cfr. Lambién, Érica para vivir mejor, Barcelona. Ariel, 1995.

16. Lanhman. Rowman and Littlefield. 1998.

¿Hacia un humanismo trans-antropocéntrico? 
En estos últimos años, Singer está orientando sus reflexiones al ámbito de la sociopolítica. Nos quiere convencer en su último libro de que hay que dejar de lado al marxismo como la fillosofía más adecuada para un cambio social progresista, y propone en cambio al darwinismo como la filosofía más adecuada para promover un movimiento de renovación social y política. Así, en Una izquierda darwiniana. Política, evolución y cooperación ${ }^{17}$, sienta las bases y las líneas de acción de un supuesto movimiento social que tome el relevo del obsoleto movimiento marxista, y se apreste a ir construyendo una nueva sociedad sobre la base de una nueva "izquierda darwiniana".

\subsection{Otros precursores}

Aunque Singer se ha convertido en el más conocido y representativo defensor de los derechos de los animales, no es ni mucho menos el iniciador de estos movimientos. Ya hemos señalado, y más adelante haremos referencia a ello de una lorma más detenida, que el propio Singer se apoya en las teorías de Bentham, cn el siglo pasado. Bentham es sin duda el gran adelantado de este tipo de teorías y posturas. Pero en el siglo pasado y en el presente siglo han existido varios precedentes. En el siglo pasado, encontramos, entre otros autores de interés, al escritor inglés Henry S. Salt ${ }^{1 k}$, y su influencia en la orientación vegetariana y no violenta de Gandhi. Ya en nuestro siglo, en 1949, Aldo Leopold defendió la tesis de la ética del suelo, consistente en extender el círculo de la comunidad ética al conjunto de la naturaleza, tanto animales como plantas, y hasta al aire y a la Tierra en su totalidad. Igualmente, Meyer Abich propuso la extensión de una legislación para defender los derechos de animales y plantas, basándose en cl parentesco que los humanos tenemos con todos ellos, en la medida en que también los seres humanos somes parte del mundo natural. Por su parte, Michel Scrres, como ya hemos señalado más arriba, propone una reorientación de los planteamientos éticos humanos que supere la estrecha idea de que sólo debe atender los contratos interhumanos para ampliar su temática a la relación del hombre con la naturaleza, basada en un "contrato natural", que respete a la naturaleza como casa del hombre y atienda al lenguaje de la Tierra, para aprender y aplicar al mundo social humano el modo como se configuran en la naturaleza las fuerzas, los lazos y las interacciones entre los diferentes seres vivos.

Otro antecedente lo constituye el empeño de David Favre, en los EEUU, de cstablecer una enmienda constitucional en la que se afirmara que "todo animal salvaje tiene derecho a una vida natural. Los humanos no pueden privarle de vida, libertad o hábitat, sin un proceso equitativo"1".

17. Barcelona. Crítica. 2000.

18. Cir. H.R. Salt, Los derechos de los animales, Madrid, Los Libros de la Catarata, 1999. La introducción de J. Mosterín ayuda a situar al autor y su militancia a favor clel vegetarianismo y los derechos de los animales.

19. D. Favre, Wildlife Rights: The Ever-Widening Circle, Environmental Law. 1976. 9, p. 9. 
También es un hito de interés la postura de Stone, quien planteó en 1972, lambién en los EEUU, el derecho a litigar ante los tribunales a favor de los árboles, en situaciones especiales. Sus argumentaciones, aunque produjeron risa en algunos, a otros les resultaron convincentes. Stone señalaba que así como en épocas anteriores tampoco se había considerado a mujeres, niños y esclavos sujetos de (lerecho. y por otro lado se consideraban sujetos éticos a entidades inanimadas, como sociedades comerciales, humanitarias, deportivas, etc., de igual modo pensaba él cue tendrá que llegar un momento en que se reconozcan los derechos de la naturaleza y de todos los seres vivos.

También en Europa ha habido autores que han propuesto en diversas naciones enmiendas constitucionales a lavor de reconocer la igualdad de derechos entre los hombres y los demás seres vivos. Tal es el caso de Leimbacher y Bosselman en Alemania, y Hermitle en Francia ${ }^{20}$.

Todos estos esfuerzos hacia la consideración de los derechos de los animales tuvicron pronto eco internacional al conseguir que la UNESCO redactara y aprobara en 1978 la "Declaración Universal de los Derechos de los Animales"21.

\subsection{Las principales tesis de Peter Singer}

Vamos a recoger de modo sintético los planteamientos más importantes de Peter Singer, para poder dialogar con él y presentar nuestros puntos de acuerdo y cle discrepancia. Un tex to que nos ayuda en esta labor es su artículo Ética más callá de los límites de la especie ${ }^{22}$. El mismo autor nos señala que este artículo es un resumen de las posturas que ha defendido en su libro Animal Liberation (1990).

La primera tesis de su teoría consiste en defender lo que llama una "ética no especicísta", en la medida en que, según Singer, la ética occidental (estamos moviéndonos siempre dentro de este horizonte cultural) "ha estado centrada en los humanos" ${ }^{23}$. Pero no hay razón para seguir manteniendo esta postura, y sí muchas razones para cambiar. Pero la pregunta que nuestro autor considera pertinente es hasta dónde debe extenderse la nueva ética. "La posición que defiendo, afirma Singer, es cjue la ética se extiende directamente a todos los seres dotados de

20. Para una visión más amplia de todos estos autores y teorías, cfrr. F. Ost, Naturaleza y derecho. Para un clebate ecológico en profundidad, Bilbao, De. Mensajero, 1996. Támbién. clir. Nicolás M. Sosa, recensión del libro de P. Cavalieri y Peter Singer, El mrovecto "gran simio". La igualdad más allá de la humanidad, en Teorema, XVIII/3 (1999). 94-96.

21. Puede encontrarse el texto íntegro en Jesús Mosterín y Jorge Riechmann, Animales y ciucladanos, Madrid, Talasa, 1995, pp. 302-304.

22. Teorema. XVIII/3 (1999), 5-16.

23. Ibídem. p. 5. A partir de ahora, las citas tomadas de este artículo las señalaré en el texlo, con el número de página entre paréntesis.

¿Hacia un humanismo trans-antropocéntrico? 
sensación, esto es: a todos los seres capaces de sentir placer o dolor. En contrastc con aquellos que quieren extender la ética a los seres no dotados de sensación tales como las plantas, o entidades como los ecosistemas. argumento que no hay ningún sentido en el que podamos incluir direclamente seres sin intereses, si hien hay muchas y muy lucrtes razones para pensar que la conservación de los hosques y cle los ecosistemas es descable, desde el punto de vista tanto de los intcreses humanos como de los seres no humanos dotados de sensación" (p. 5).

Como puede verse. Singer quiere oponerse a lo que él considera un prejuicio ético hoy ya no aceptable. consistente en entender que los miembros de la especic humana tienen más valor o dignidad que todos los demás seres vivos.

Su postura, atendiendo también a las palabras citadas más arriba, se distingue claramente de la de los ecologistas que él llama "profundos". Coincide con cllos en extender la ética más allá de los límites de la especie humana, pero se distancia a la hora de proponer hasta dónde liene que extenderse la nueva frontera de la ética. Para los "ecologistas profundos", está claro que el límite llega hasta donde llega la vida, atribuyendo los mismos derechos a todos los seres que componen el ámbito de la biosfercı. En cambio, para Singer, la ética sólo hay que extenderla hasta aquellos animales dotados de sensaciones, y por tanto, capaces de tener y clelender sus propios intereses, esto es, liundamentalmente los grandes simios.

Ha cle aclararse desde el principio, y es la segunda tesis de Singer, que el modelo de ética que sigue es el urilirarista (en la línea de Jeremy Bentham, John Stuart Mill y Henry Sidgwick) $)^{24}$, en la medida en que "juzga un acto como correcto o erróneo preguntando si llevará a un superávit mayor de placer sobre el dolor que cualquier otro acto, que esté abierto al agente" (p. 6). Los utilitaristas clásicos, cmpezando por J. Bentham ${ }^{25}$, auténtico precursor de este modo de pensar, consideraban que no son los humanos los únicos seres vivos capaces de experimentar "placer" y "dolor", sino también los animales. Por tanto, habrá que justificar claramente por qué se entiende que la moral ha de extenderse a todos los seres que lienen scnsaciones, dolor o placer, y delimitar con claridad qué se entiende por sensaciones.

Singer entiende que este modo de entender la ética se distancia fuertemente de las premisas que sostienen la ética dominante en la cultura occidental, basada en la tradición judeocristiana. Para esta ética, parece que sólo los humanos son moralmente relevantes, habiendo recibido de Dios (cfi. Génesis, 1, 24-28) el mandato de dominar la tierra. Para esta mentalidad, señala Singer, "la naturaleza

24. Sobre el utilitarismo, cfr. Will Kymlicka. Filosofía politica contemporánea. Una introducción. Barcelona, Ariel. 1995; Fco. Vergara, Introducción a los fundamentos. fillosóficos al liberalismo. Madrid. Alianza, 1998.

25. Cfr. J. Bentham. Introduction to the Principles of Morals and Legislation Oxford. Clarendon. 1996. calp. 17. Cfr. Peter Singer, Liberación animal. o.c.. cap. I". 
misma no tiene valor intrínseco alguno, y la destrucción de las plantas y los animales no puede ser pecaminosa, a menos que mediante su destrucción dañemos a los seres humanos" (p. 7). En realidad, el desmarque que Singer hace de la élica judeocristiana es bastante poco matizado, en la medida en que dentro de ese horizonte cultural hay que distinguir, por un lado, la postura fundamentalista denominada "creacionismo" (que se opone radicalmente a la teoría darwinista) ${ }^{26}, y$, por otro, las diferentes posturas dentro del ámbito del cristianismo, que van desde posiciones más antropocéntricas y negadoras de ningún tipo de "derechos" para los animales, hasta los que entienden que es compatible defender determinados derechos de los animales y mantener una diferencia ontológica entre hombres y animales. Pero tendremos ocasión más delante de precisar más estas posturas.

Avanzando en la reflexión, y entramos en el tercer aspecto del problema, se trata de preguntarse "si existe algo que tenga valor intrínseco más allá de los sercs humanos" (p. 7). Para Kant, en su Crítica de la razón práctica, estaba bien claro cue sólo el ser humano, dentro de los seres intramundanos, posee "valor intrínseco", esto es, sólo el ser humano es un fin en sí mismo y no puede ser usado como medio al servicio de nada ni de nadie. Por tanto, cuando entren en colisión intereses de hombres y de animales, está claro que son preferentes los de los primeros, siendo los animales unos medios al servicio de los humanos.

Para Singer, este modo de entender las cosas no es adecuado, puesto que tiene la pretensión de poder demostrar que determinados animales también deben ser considerados como fïnes y no como medios al servicio de los humanos. Claro que este punto de vista resulta novedoso, y difícil de aceptar por mucha gente. Pero cree Singer que en este punto va a ocurrir lo mismo que ha pasado respecto a la valoración que han tenido los humanos sobre la esclavitud: se ha ido cambiando las posturas de tal manera que de defenderla como correcta desde la antigüedad, incluso por filósofos de la talla de Aristóteles, se ha pasado a considerarla éticamente reprobable, a partir del siglo pasado. Singer está convencido de que el avance de la sensibilidad ética se encargará igualmente de hacer ver a los humanos que el trato que se concede en la actualidad a determinados animales es reprobable éticamente y, por tanto, tiene que cambiar.

La razón por la que Singer defiende la dignidad ética de los animales, y es el cuarto aspecto de esta reflexión, es que los animales, al igual que los humanos.

26. Es importante advertir que desde ciertas posturas clarwinistas se tiende a meter en el mismo saco a quienes se denominan "creacionistas" (postura fundamentalista en la intcrpretación bíblica, y fuertemente representada en varios estados cle los Estados Unidos) y diferentes posturas cristianas que no ven problema en conjugar una interpretación clarwinista del proceso evolutivo con la creencia en la acción creadora de Dios. Sobre el "creacionismo", cfr. Willem B. Drees. Creacionismo y evolución. Concilium, 2000, $\mathrm{N}^{\circ}$ 284, 55-64: Evolución y fe, $\mathrm{N}^{\circ}$ monográfico de Concilium, 2000, $\mathrm{N}^{n}$ 284; Diego Núñez, La religión y la ciencia (Historia cle las controversias entre ambas), Mundo Cientítico, 1996, N 166, 247-256. 
pueden experimentar dolor, así como placer y felicidad. Entiende Singer que el argumento central que la ética antropocéntrica o humanista ha mantenido siempre para defender la diferencia esencial u ontológica entre hombres y animales ha sido la racionalidad como atributo de los primeros (animal racional es la definición más común del ser humano), esto es, la capacidad de los humanos de pensar, de ser conscientes de sus acciones, de prever el futuro, etc.

Pero estos argumentos no son suficientes para Singer. Reconoce efectivamente que en el promedio general sí es cierto que hay una clara ventaja de nuestra especie respecto a las demás, con relación a esas capacidades racionales. Pero también parece claro para Singer que "los perros, los caballos, los cerdos y otros mamíferos son capaces de razonar mejor que los humanos recién nacidos, o que los humanos con minusvalías intelectuales profundas" (p. 10). Aquí nos encontramos, pues, con una de las tesis más importantes de la argumentación del pensador australiano: si la razón para situar a los humanos en un peldaño más elevado que los animales es la racionalidad, está claro que determinados animales dan muestras de mayor racionalidad e inteligencia que determinados colectivos considerados "humanos" y dotados de dignidad ética, como son los niños recién nacidos y los "humanos con minusvalías intelectuales profundas". La conclusión evidente para Singer es que si concedemos derechos a estos colectivos, se los tenemos que dar también a ciertos animales; y si les negamos los derechos a estos animales, se los tendríamos que negar a niños y minusválidos psíquicos.

Lo que hace al parecer justificable y comprensible la prohibición de hacer daño a niños y a minusválidos, dentro de la ética tradicional, es la experiencia que tenemos de que son capaces de experimentar dolor. Entra, por tanto, aquí el factor "compasión". Y eso es lo que consideramos como factor determinante de prohibición de causarles ningún mal, y no en cambio el hecho de que tengan racionalidad/consciencia o no.

La conclusión que extrae Singer de todo esto es que "mientras que la tradición occidental dominante está equivocada sobre la cuestión substantiva de cómo deberíamos considerar a los animales no humanos, esta misma tradición tiene dentro de sí los instrumentos (su reconocimiento del papel de la razón y del argumento) para construir una ética extendida que alcance más allá de los límites de la especie y aborde las relaciones entre los humanos y los animales. El principio que tiene que aplicarse es el de igual consideración de intereses. Las dificultades restantes residen en cómo ha de aplicarse exactamente este principio a los seres con vidas (tanto mentales como físicas) que son muy diferentes de la nuestra" (p. 10).

\subsection{Supuesto continuador de la tradición ilustrada y humanista}

Peter Singer es consciente, como ya hemos tenido ocasión de ver, que sus tesis sobrepasan los planteamientos éticos y cosmovisionales dominantes de la 
tradición occidental. Pero no considera que rompe con ella, sino que empalma con lo más valioso de la misma: la corriente ilustrada y humanista.

En respuesta al filósofo francés Luc Ferry ${ }^{27}$, que le acusa de que sus teorías rompen y se distancian de lo más valioso de la tradición ilustrada, entiende que no es así. L. Ferry considera que teorías como las de Singer se desmarcan de la línea ilustrada y se sitúan en la tradición romántica alemana, tendente a una cierta divinización de la naturaleza. Incluso se hallaría también Singer peligrosamente cercano a la postura nazi en el modo de concebir nuestras relaciones con la naturaleza.

Sí es cierto, piensa Singer, que su pensamiento supera la corriente antropocéntrica de determinados ilustrados, como Descartes y Kant, para quienes la diferencia entre hombres y animales es cualitativa y ontológica, pero entiende que hay otra línea ilustrada, como es el caso de J. Bentham, que defiende la necesidad de romper la barrera ética entre hombres y animales y conceder a éstos determinados derechos, basándose en la capacidad de sentir dolor y placer ${ }^{2 x}$.

Por eso, su movimiento de "liberación animal" lo ve claramente emparentado con la línea emancipadora de la ilustración, sólo que ahora se trata de ampliar el ámbito de liberación también a los animales, sobre todo a una serie cle especies, los grandes simios, muy cercanos a nosotros, según él, en su capacidad racional y sensible. Por tanto, y en discrepancia con L. Ferry, "es precisamente, afirma Singer, el universalismo abstracto de la ilustración, no la tradición romántica, lo que constituye la base del movimiento de liberación animal" (p. 11).

En esa misma línea, entiende Singer que sus planteamientos pueden considerarse también situados dentro de la gran y amplia corriente humanista, puesto que el concepto "humanismo" entiende que encierra muy diversas acepciones. Hay, en primer lugar, un humcinismo religioso, consistente en afirmar que entre el hombre y los animales hay una diferencia esencial, porque Dios ha creado al ser humano a su imagen y le ha dotado de una especial densidad ontológica y ética. Hay un humanismo antropocéntrico, que coincide con el anterior en defender la diferencia ontológica entre hombres y animales, pero sin recurrir a Dios para su fundamentación. Singer no está de acuerdo con el primer humanismo, "puesto que no creo en la existencia de Dios, no puedo pensar que la ética sea un sistema de órdenes divinas"(p. 12). De ahí que no le siente mal que le denominen algunos creyentes "humanista sccular". Pero también se desmarca del "humanismo antropocéntrico", teoría que considera errónea, "tanto ética como científicamente" (p. 13).

El humanismo que considera más correcto (aunque no le pone ningún adjelivo $)^{2 "}$. es el que amplía los "derechos humanos" a los animales superiores. De ahí

27. Cir. Luc Ferry, Le nouvel Ordre Écologique. París, Grassel, 1992.

28. Cli. Gary L. Francione. El error de Bentham (y el de Singer). o.c.

29. Quizás podría denominarse "humanismo trans-antropocéntrico". con todo lo que licne de contraditio in terminis. 
que proclame que "es hora de pasar del humanismo antropocéntrico a una ética hasada en la preocupación amplia y compasiva por el suf rimiento de los otros, y un rechazo de todo fanatismo religioso o ideológico" (p. 13$)^{30}$.

En resumen, su propuesta la considera emancipadora, liberadora y revolucionaria, en la línea de los grandes movimientos de liberación que se han producido en la historia occidental de los últimos siglos. Incluso, considera que su movimiento de liberación de los animales resulta más ventajoso para la especie humana que las propuestas del "humanismo antropocéntrico". Y además, resulta más progresista y liberador, en clave sociopolítica, que las tesis marxistas.

\subsection{Una "izquierda darwiniana"}

Para Singer es evidente que el progresismo actual pasa por aceptar como hase teórica principal la filosofía darwinista, que ha dejado en evidencia la obsolescencia del marxismo tradicional. Esta es la tesis central, como ya quedó apuntado más arriba, de su último libro, titulado significativamente Una izquiercla clarwiniana. Política, evolución y cooperación ${ }^{31}$.

Singer se sitúa entre quienes consideran que el programa político del marxismo ha fracasado. Y la razón de ello es que Marx se equivocó respecto a la idea que tenía sobre la naturaleza humana ${ }^{32}$. Singer cita las palabras de Marx sobre la forma cle cntender la naturaleza humana a propósito del comentario sobre las Tesis sobre Fencrbach: “... la esencia del hombre no es una abstracción inherente a cada uno de los individuos. En realidad consiste en el conjunto de las relaciones socialcs". Y comenta Singer: "De esta creencia se sigue que, si se puede cambiar por completo el "conjunto de las relaciones sociales", se puede cambiar toda la naturalčal humana" (p.13). Esta forma de pensar, entiende Singer, es hásica en el marxismo y afecta de lleno al pensamiento básico de toda la izquierda.

El centro de la discusión y de la discrepancia entre Singer y el marxismo cstaría, por tanto, en el modo de entender la naturaleza humana, y, en concreto, en el modo como conjuga cada una de las teorías la tan debatida y capital cuestión de cómo entender la relación en la naturaleza humana cntre lo innatohiológrico y lo aprendido-ambiental. Singer no está de acuerdo en considerar que

30. En este punto reconoce honestamente Singer que también dentro de su movimiento haly fanáticos, y los reprucba: "Sí, renocozco que hay lanáticos entre los partidarios de la liberación animal. como los hay en cualquier movimiento amplio. y que reciben una atención desproporcionada en los medios de comunicación. Sin embargo, son una peçueñísima minoría dentro del movimiento, y no una representación auténtica (le su lilosofía": o.c.. pp. 12-13.

31. Barcelona. Crílica, 2000). Este pequeño libro de bolsillo es la aportación de Peter Singer al Darwin Seminars, organizado por la London School of Economics.

32. Cirr. ibídem. pp. 12-13. A partir de ahora, las citas de este libro irán en el texio, con el número cle página entre parćntesis.

\section{0}

Realidad 80, 2001 
lo fundamental de lo humano está en el aprendizaje, sino en sus características biológico-genéticas. El marxismo habría demostrado con su fracaso político concreto la falsedad de sus presupuestos antropológicos.

La conclusión para Singer es que "la izquierda necesita un nuevo paradigma" (p. 13). Entiende que estamos en una nueva situación mundial, movida por una globalización que abarca a todo el planeta, y ya no sirven las viejas tesis del internacionalismo socialista y obrerista. El ansia progresista de la humanidad necesita nuevas teorías que le lleven a conseguir una sociedad mejor. La izquierda necesita ideas e impulsos nuevos, y eso es lo que quiere aportar Singer. Para ello, hay que tener las ideas claras sobre cuál es la auténtica naturaleza del ser humano y cuáles son las reglas que rigen su comportamiento social, político y cconómico. Por eso, nos dice Singer, "ha llegado el momento en que la izquierda se tome en serio el hecho de que somos animales evolucionados y de que llevamos el sello de nuestra herencia, no sólo en la anatomía y en el ADN, sino también en nuestro comportamiento. En otras palabras, ha llegado el momento de desarrollar una izquierda darwiniana" (p. 15).

Singer se hace a continuación la pregunta que hoy día se hace tanta gente: ¿qué es ser hoy de izquierdas? ¿Qué es lo esencial en la actualidad para la izquierda? Y su respuesta la da a través de la experiencia personal de su amigo y admirador, Henry Spira, sobre cuya trayectoria de militante por una sociedad mejor escribió uno de sus últimos libros, como ya dijimos con anterioridad ${ }^{33}$. Tanto para Spira como para Singer, ser de izquierda es "estar de parte del débil, no del poderoso; del oprimido, no del opresor; de la montura, no del jinete" (p. 17). Pero para estos activistas el dolor y el sufrimiento de nuestro mundo no se limita al que padecen tantos seres humanos alienados y esclavizados o torturados y matados, sino que su compasión se extiende también al ámbito de los animales, que constiluyen "otro grupo de seres explotados que necesitan ayuda" (p. 17).

Al buscar Singer apoyo en el darwinismo, tiene mucho cuidado en hacer ver que su postura no cae en la llamada "falacia naturalista", consistente en deducir, como lo han hecho determinados biologistas" ${ }^{24}$, el "deber ser" del "ser", esto es, deducir los valores y orientaciones éticas de las leyes biológicas o genéticas de lá especie humana. El propio Singer tiene un gran interés en defenderse de ello, y en desmarcarse de cualquier "darwinismo social"

33. Cfr. Ethics into Action. Henry Spira and The Animal Liberation Mouvement, o. c.

34. Cfr. Fco. J. Ayala, Origen y evolución del hombre, Madrid, Alianza, 1980, cap. $7^{\circ}$.

3.5. Se denomina "darwinismo social" a la teoría, defendida por H. Spencer, consistente en aplicar a la sociedad humana los parámetros estrictos de la selección natural, presentes en el ámbito de la biología. Cfr. H. Spencer. The Man versus the State. Indianapolis, Liberty Classics, 1981 (trad. cast., "El individuo contra el Estado". Barcelona. Orbis, 1985).

¿Hacia un humanismo trans-antropocéntrlco? 
E.O. Wilson ${ }^{36}$. Por tanto, entiende que del darwinismo sin más, se puede deducir tanto posturas de derecha como de izquierda. Así, para Singer, el darwinismo, como cualquier otra teoría científica, lo único que hace es aportar "información relevante para que nosotros decidamos" (p. 28). Y esa información relevante es la que nos permite defender determinadas ideas sobre la naturaleza humana y considerar incorrecta la idea que tienen sobre el ser humano otras teorías que no concuerdan con estos datos científicos aportados por el darwinismo.

Y para completar esta idea, Singer se detiene en mostrar los malentendidos que la izquierda marxista ha defendido o propalado con anterioridad sobre el darwinismo. En concreto, se refiere en primer lugar a las conocidas teorías de Pedro Kropotkin, en La ayuda mutua. Un factor de la evolución ${ }^{37}$. Para Kropotkin, tan importante como la agresividad en la lucha por la vida de la que habla la teoría de la selección natural es la cooperación y la ayuda mutua. De tal modo que, según Kropotkin, los seres humanos son cooperativos por naturaleza. La agresividad y la violencia que vemos en las sociedades son debidas a los malos gobiernos, que originan y consienten las enormes desigualdades entre los hombres, ocasionando así los crímenes y agresiones mutuas. Estos planteamientos anarquistas alcjaban a Kropotkin de los marxistas oficiales.

En realidad, Marx y Engels vieron en un principio en las teorías de Darwin un apoyo científico a sus planteamientos sobre la lucha de clases. Pero, en opinión de Singer, no entendieron bien a Darwin, puesto que pensaban que éste delendía, como Lamarck, la herencia de los caracteres adquiridos ${ }^{3 k}$. En ese sentido. Singer entiende perfectamente que "la teoría materialista de la historia implica que no existe una naturaleza humana fija. Se transforma con cada cambio del modo de producción" (p. 37). Pero este modo de entender la naturaleza humana no es original de Marx. En realidad, es una teoría muy presente en el pensamiento occidental.

Y aquí está, según Singer, la razón del rechazo por la izquierda del pensamiento darwiniano: la creencia en la perfectibilidad del hombre. Tal convencimiento se daría ya desde Platón y sus sueños de construir una sociedad perfecta. "Durante todo el tiempo que existe, la izquierda ha pretendido una sociedad en

36. Sobre la "sociobiología", cfr. E.O. Wilson, La sociobiologia. La nueva síntesis, Barcelona. Omega, 1980; Id., "Sobre la naturaleza humana", México, F.C.E., 1980; M. Rusc, Sociobiologia, Madrid, Cátedra. 1983; C. Beorlegui, El reto de la biologia a la antropología. De la etologia a la sociobiologia, Letas de Deusto, 16 (1986), No 34, 37-69.

37. Cfr. P. Kropotkin, Mutual Aid: A Factor of Evolution, Londres, Heinemann, 1902 (trad. cast.. Madrid, Zero-Zyx, 1978).

38. Aquí estaría, según Singer, el origen del desdichado afair del genetista ruso R.D. Lysenko, en tiempos de Stalin (cfi.. Peter Singer, "Una izquierda darwiniana". o.c., p. 35-36). Sobre el caso Lysenko, cfr. The Open University, Historia y relaciones sociales de la genética, Barcelona, Ed. Fontalba, 1983, 86-96. 
la que todos los seres humanos vivan armoniosa y cooperativamente con todos los demás, en paz y en libertad" (p. 39). Marx y Engels perseguían este sueño, y estaban convencidos de haber descubierto las leyes de la historia que la orientarían infaliblemente a esa situación perfecta, en la que la ley ética que la regiría no sería otra que "de cada cual según sus capacidades, a cada cual según sus necesidades".

En cambio. según Singer, la teoría darwinista nunca ha defendido que la evolución y la historia humana avancen a un final ya presabido. "Para Darwin, la lucha por la vida, o por lo menos por la existencia de la propia progenie, no tiene linal. Esto se sitúa muy lejos del sueño de perfeccionar la humanidad" (p. 42). Mientras los marxistas consideraban que los vicios y males de los hombres son consecuencia de vivir en una sociedad injusta, con propiedad privada de los medios de producción, los darwinistas piensan que tales males están en y proceden de la naturaleza biológica del ser humano.

Le resulta curioso a Singer que "dos ideologías tan distintas como el cristianismo y el marxismo están mutuamente de acuerdo en insistir en el abismo que separa a los hombres de los animales; por tanto, en insistir en que la teoría evolucionista no puede aplicarse a los seres humanos" (p.43) ${ }^{30}$. El problema de Singer en este tipo de planteamientos es que realiza a veces afirmaciones poco matizadas. a la hora de entender cómo sc configura la conducta y el comportamiento humano. A veces parece dar a entender que no puede haber más que dos planteamientos extremos: o se defiende que las leyes de conducta están sólo en la naturaleza biológica del hombre (darwinismo), o se defiende que esas leyes las confecciona arbitrariamente el ser humano, al margen de sus bases biológicas (marxismo y cristianismo). El problema, como hace tiempo lo han resuelto las más sensatas teorías psicosociológicas, es más complejo y se explica conjugando ambos vectores, el biológico-genético y el ambiental, sin saberse en cada momento distinguir la parte de la conducta que corresponde a cada una de las dos vertientes ${ }^{\text {t) }}$.

39. Resulta a nuestro entender problemático, y más bien incorrecto y simplón, decir que el marxismo y el cristianismo defiendan que el darwinismo "no puede aplicarse a los seres humanos". Tal vez estaríamos de acuerdo si se nos dice que ambas teorías, o determinadas corrientes de pensamiento dentro de ambas teorías, están de acuerdo en scñalar que "determinadas interpretaciones del darwinismo" (entendido, por ejemplo, como un modo reductivo y biologista de interpretar el mundo de la biosfera) no puede aplicarse al ser humano. Y ello se debe a que Singer habla sin matices del "darwinismo", como si todo el mundo tuviera claro y coincidiera en todos los aspectos que se encierran tras esa etiqueta.

40. Cfir. R.C. Lewontin. S. Rose y L.J. Kamin, No está en los genes. Racismo, genética e ideología. Barcelona, Crítica, 1987; R.C. Lewontin, La diversidad humana. Barcelona. Labor, 1984: VV.AA.. La biologia como arma social, Madrid, Ed. Alhambra, 1982: ¿Genética o entorno? ¿Biología o cultura? ¿Estamos determinados por los genes?? Nºnográfico de "Mundo Científico", 1998, N 194. 
Singer no defiende, claro está, que la naturaleza humana es producto exclusivamente de la biología. Pero considera que es más determinante lo biológico que lo cultural. Para defender esto, se apoya en las investigaciones de la etología animal y en ciertos antropólogos culturales, para concluir que "si bien en algunos campos de la vida humana muestra mayor diversidad, en otros el comportamiento humano se mantiene bastante constante en todo lo ancho de las culturas humanas, $y$ algunos aspectos de nuestra conducta la compartimos asimismo con nuestros parientes no humanos más próximos" (p. 51 ).

Singer se pregunta a continuación qué aspectos podemos considerar fijos y cuáles variables dentro de la naturaleza humana. Para responder mejor a esta cueslión, divide los diversos aspectos de la vida humana en tres campos, según comporten muchas, pocas o casi ninguna variación. Dentro del ámbito de aspectos culturales que permiten grandes variaciones, sitúa "los procedimientos con que producimos los alimentos", que pueden ser por recolección, caza, agricultura, ganadería, elc. En el segundo ámbito, el que admite algunas variaciones, sitúa las rclaciones sexuales, así como la identilicación élnica, la xenofobia y cl racismo. Y dentro del campo en que se producen pocas variaciones, porque aparecen en todas las culturas, sitúa el hecho de ser seres sociales, nuestra preocupación por los parientes, la disposición a la cooperación, la existencia de las jerarquías sociales, y los roles scxuales (clir. pp. 51-58).

La verdad es que, a la vista de estos argumentos, uno está inclinado a pensar que por este camino Singer no puede llega muy lejos a la hora de mostrar que la naluralcza humana no es tan perfectible como quieren defender marxistas, cristianos y otras tendencias. De todos modos, lo que Singer quiere demostrarnos cs que lo biológico es más fundamental que lo cultural a la hora de configurar la conducta humani. De hecho, piensa Singer que los que quieran cambiar la socicdad, como sin duda han pretendido marxistas y cristianos, no deben guiarse por la ingenua crecncia de hacer una sociedad altruista, basada en la idea de que somos caritativos y altruistas por naturaleza. Lo que la visión darwinista de la naturaleza humana nos dice es que los hombres buscan siempre su propio interés. En ese sentido, encuentra acertada la versión que G. Hardin hace de la regla de oro de este modo de actuar: "nunca pedir a nadie que actúe contra sus propios intereses" +1 .

Claro que Singer se cuida muy bien de señalar que no se debe entender esta húsqueda del "propio interés" desde el exclusivo punto de vista economista. Los scres humanos perseguimos no siempre dinero; de hecho, "nos interesa más ser lelices que ser ricos" ( $p .61$ ). El dinero es sólo un medio. Otros aspectos del propio interés son, para Singer, sentirse queridos, ser útiles, pertenecer a una

41. Clir. Garret Hardin, The Limits of Altruism: An Ecologist's View of Surviral, Bloomington. Indiana University Press, 1977. 
comunidad, y otra serie de aspectos que, según él, "es más probable que se deriven de cooperar que de competir con otros" (p. 61).

En resumen, el modo como el darwinismo moderno entiende la naturaleza humana es una mezcla dialéctica entre "competencia" y "altruismo recíproco" o "cooperación". Estos dos ingredientes aparecen en todas las sociedades, pero en diferente proporción. No podemos cambiar ese hecho, pero tal vez sí la proporcionalidad de cada componente. Pero está claro para Singer que "una sociedad cooperativa está más acorde con los valores de la izquierda que una sociedad competitiva" (p. 64). Fomentar la competitividad ha generado más riqueza, pero también más desigualdad.

Los estudios de R. Axelrod ${ }^{42}$, D. Hamilton ${ }^{43}$ y otros sobre la cooperación humana. basándose en la "reoría de los juegos" y en "el dilema del prisionero" +" muestran que la tendencia de los seres humanos es más fuerte a cooperar que a ser egoístas. porque se gana más a la larga con la primera estrategia conductal que con la segunda.

Con este modo de ver las cosas, advierte Singer que el darwinismo moderno ya no defiende posturas tan competitivas y egoístas como el darwinismo social del siglo XIX, sino unas posturas que tienden a promover actitudes más cooperativas, porque son una estrategia que a la larga beneficia a toclos, y no produce tantas desigualdades y pobreza como el darwinismo social. Incluso piensa Singer que se puede orientar a la sociedad para que dé el salto de la cooperación al altruismo. Desde posturas sociobiológicas, se ha estudiado el fenómeno del altruis$\mathrm{mo}^{+5.5}$, para concluir que, aunque no somos altruistas por naturaleza, la cstrategia altruista (tan contraria, al parecer, con la regla central de los seres vivos: "el egoísmo genético") se ha mantenido en el proceso evolutivo, porque es una estrategia beneficiosa para los individuos. Pero ha de advertirse que cuando los sociobiólogos hablan de "altruismo", lo entienden como una estrategia que encierra, en el fondo, una perspectiva egoísta: somos "altruistas" porque salimos con ello más beneficiados que si persiguiéramos directamente objetivos egoístas.

En resumen, Singer nos propone las tesis centrales que, según él, la izquierda darwiniana debe aceptar y las que debe rechazar. Las tesis centrales que, según él, hay que defender son las siguientes:

42. Cfir. Robert Axelrod, The Evolution of Cooperation. Basic Books, 1984.

43. Cli. W.D. Hamilton, Altruism and related phemonena, mainly in social insects, Ann. Rev. Ecol. Syst., 1972. 3, 193-232.

44. Entre la abundantísima bibliografía sobre la "teoría de los juegos". cfrr. W. Poundstone. El dilema del prisionero (Joln von Neumann, la teoria de los juegos y la bomba), Madrid, Alianza. 1957: Morton D. Davis, Teoria de juegos, Madrid. Alianza, 1971: E. S. Venttsel, Introducción a la teoría de los juegos, México. De. Limusa, 1973.

45. Clir. las obras de E.O. Wilson, citadas en la nota 36; además, R. Dawkins. "El gen egoísta", Barcelona, Labor, 1979; M. Ruse. "Sociobiología", o.c. 
1. “Aceptar que existe algo así como una naturaleza humana y tratar de saber más de ésta, de modo que las medidas políticas puedan basarse en los mejores datos disponibles sobre cómo son los seres humanos".

2. "Rechazar toda inferencia que deduzca de lo que es "natural" lo que es "correcto"”'.

3. "Contar con que, en los distintos sistemas sociales y económicos, muchas personas actuarán de forma competitiva con objeto de realzar su estatus, ganar posiciones de poder y/o mejorar los intereses propios y de sus parientes"

4. "Contar con que, al margen del sistema social y económico en que vivan, la mayor parte de las personas responderán positivamente a las oportunidades auténticas de participar en formas de cooperación mutuamente beneficiosas".

5. "Promover estructuras que estimulen la cooperación y no la competencia, y tratar de canalizar la competencia hacia objetivos socialmente deseables".

6. "Reconocer que la forma en que explotamos a los animales no humanos es una herencia del pasado predarwiniano que exageró el abismo entre los humanos y los demás animales, y por lo tanto procurar un mejor estatus moral para los animales no humanos y una visión menos antropocéntrica de nuestro dominio sobre la naturaleza".

7. "Mantener los valores tradicionales de la izquierda, como ponerse de parte de los débiles, los pobres y los oprimidos, pero reflexionar cuidadosamente sobre qué cambios sociales y económicos les beneficiarán verdaderamente" (pp. 86-87).

\section{3. ¿Un nuevo replanteamiento de la antropología, la ética y la sociología?}

Tras este esquemático recorrido por la obra teórica de Peter Singer, ha llegado el momento de posicionarnos ante ella y expresar razonadamente lo que consideramos aciertos y errores en su planteamiento. Como puede verse, Singer ha ido construyendo a lo largo de sus diversos escritos un sistema completo de pensamiento, con una teoría sobre el ser humano, su naturaleza, sobre los principios fundamentales que deben regir una ética adecuada, y un proyecto sociológico sobre la especie humana, que viva en paz consigo mismo y con la naturaleza, respetando a las demás especies animales.

A pesar de ello, entendemos que el punto clave de su teoría es su idea del ser humano, de modo que todos los demás elementos de su sistema se sostienen y tienen sentido en función de su concepción de la naturaleza humana, y se cae estrepitosamente si cae previamente su modelo antropológico. Por eso, a continuación vamos a tratar de analizar críticamente su modelo de ser humano, para posteriormente hacer lo mismo con su ética y su propuesta sociológica. 


\subsection{Una insuficiente concepción de lo humano}

El punto de arranque de las reflexiones de Singer consiste en afirmar que es un error establecer una diferencia cualitativa u ontológica entre la especie humana y las demás especies animales. Por ello, critica los planteamientos de los humanismos antropocéntricos, sean creyentes o no. El error de estos humanismos, en opinión de Singer, es que proponen como rasgo distintivo del ser humano la racionalidad. Pero esta estrategia diferenciadora no es pertinente, asegura Singer, puesto que existen muchos animales (los grandes simios, sobre todo) que muestran una mayor inteligencia/racionalidad en sus conductas que determinados colectivos humanos (niños pequeños y deficientes mentales). De ahí que haya que optar por elegir entre una alternativa cuyos dos extremos parecen inaceptables para los humanistas: considerar no humanos ( $y$, por tanto, no sujetos éticos) a niños y defïcientes mentales, o bien aceptar en el colectivo de "personas" a estos animales que muestran una especial inteligencia. A diferencia de esos humanismos, Singer considera aceptable esta segunda alternativa.

El argumento que ya hemos visto utilizar a Singer es trasladar de la racionalidad a la sensibilidad el criterio de demarcación de "persona" y de sujeto ético. Serán personas, y por tanto dignos de derechos "humanos", todo aquel animal, humano o no, que sea capaz de sentir, de experimentar dolor y placer o felicidad, y por tanto poder atribuirle intereses. Porque, en la medida en que tenga intereses, será una falta élica ir contra tales intereses y povocarles algún tipo de sufirimiento. Ya vimos que en esto no hace más que seguir los pasos del filósofo inglés $\mathrm{J}$. Bentham ${ }^{4 h}$. Claro que para dar solidez a su postura se apoya en su concepción utilitarista de la ćtica. El utilitarismo no considera válido para fundamentar la ética hacer referencia a una visión esencialista de los seres, como hacen las posturas "intuicionistas" o "fenomenológicas", que atribuyen un valor especial a determinadas cosas, valor que sería intrínseco o inherente ("inherentismo" denominan algunos a esta postura ${ }^{47}$ ) a ellas (los seres humanos, en este caso). En cambio, a su postura la denominan los utilitaristas consecuencialista: se fijan en las consecuencias de sus acciones para juzgarlas como buenas o malas. En el caso de Singer, nucstras acciones serán buenas o malas si causan felicidad o sufrimicnto a cualquier miembro del colectivo de "personas", que para Singer comprende los seres humanos y las diferentes especies encerradas en los grandes simios.

46. Singer cita a Bentham, cuando indica que no es la capacidad de razonar sino la de sufirir como "la característica básica que le otorga a un ser el derecho a una consideración igual", y por tanto a no ser torturado. Bentham afirmaba: "No debemos preguntarnos (rcspecto a los animales no humanos): ¿pueden razonar?. ni tampoco: i.pueden hablar'?. sino : ¿pueden sufrir?" Cfr. Singer, Liberación Animal, o.c., p. 43.

47. Clr. Priscilla Cohn, Una concepción inherentista de los animales. Teorema, XVIII/3 (1999), pp. 85-1()1. 
Creemos que Singer está cometiendo varias equivocaciones, que vamos a laatar de mostrar. Cuando las posturas humanistas sitúan el criterio de diferenciación entre hombres y animales en la racionalidad, entienden por tal racionalidad, algo más amplio de lo que Singer parece dar a entender. Ya M. Scheler, en su celebrado libro El puesto del hombre en el cosmos (1928) $)^{\text {th }}$. atribuyc "intcli¿encia práctica" a los animales superiores, sin necesitar por ello de atribuirles una dignidad ética similar a los seres humanos. Y la razón de ello es que emplcamos el concepto de "inteligencia" o "racionalidad" cle formas muy diversas, algunas de ellas crróneas.

Si cntendemos por "intcligencia" la simple capacidad de reaccionar ante el ambientc, con objeto de escapar de los peligros y acercarnos a lo que nos favorecc, tendríamos que conceder la "inteligencia" a todos los seres vivos, incluso a las plantas, puesto que se trata de un instrumento dado a los seres vivos para sobrevivir en la lucha por la vida ${ }^{4 \prime \prime}$. Incluso si consideramos cl concepto de Scheler, "intcligencia práctica", como una cualidad presente en determinados chimpancćs, y consistente en la capacidad de rcsolver problemas que se le presentan al animal por primera vez, se trata siempre de una estrategia técnica de superar problemas de supervivencia.

En cambio, la racionalidad humana es mucho más abarcadora, conteniendo, adcmás de esa dimensión de "inteligencia práctica". otros muchos aspectos que abarcan desde el lenguaje, hasta la capacidad de preguntase por el sentido de la vida y nuestra posible trascendencia. Es verdad que experimentos con determinados chimpancés y gorilas han puesto sobre la mesa la posibilidad de que exista en csas especies una cierta capacidad de lenguaje, de consciencia de sí y de transmisión de cultura ${ }^{\text {s11 }}$. Pero, aparte de que estudiosos importantes, como toda la escuela de Chomsky, han puesto en entredicho estas interpretaciones tan optimistas, señalando que en esos casos de lenguaje y de supuesta inteligencia no se da más que un caso más, aunque más perfecto, de amaestramiento animal basado en el luncionamiento de los "reflejos condicionados" de Pavlov, no tendríamos ningún reparo en admitir, para el caso del lenguaje como también de las supuestas "culturas" animales y los casos de "conciencia", la idea defendida por J. Ruffié de que la especie humana no innova nada, sino que lleva hasta el extremo lo que ya aparece

48. Cir. M. Scheller. "El puesto del hombre en el cosmos", Buenos Aires, Losada, 1938. Clir. C. Beorlegui, Antropología filosófica. Nosotros: urdimbre solidaria y responsable, Bilbao, Universidad de Deusto, 1999, cap. 6², pp. 333-364, donde realizo un amplio estudio de la antropología de M. Scheler.

49. Cii: el interesante libro de K. Lorenz, La otra cara del espejo, Barcelona, Plaza y Janés. 1980.

50). Para una introducción en la problemática y en la bibliografía sobre el tema. cfir. L. Peña. "¿Somos los únicos animales racionales'?", Limbo. No 9 (1999), pp. 17-41 (este trabajo está dentro de Teorema, XVIII/3 (1999). 
en embrión en las especies más cercanas a él". En ese sentido, entre el scr humano y el conjunto de las especies que componen la bioslera, se da tanto continuidad como ruptura, en una conjugación que más adelante explicaremos.

Por tanto, cuando hablamos de "inteligencia animal", lo mismo que cuando en relación a las computadoras hablamos de "inteligencia artificial", es lundamental que tengamos presente que escribimos la palabra entre comillas, dado que su significado es analógico respecto a la inteligencia humana. Algunos autores consideran que habría que hablar de "listura" animal y artificial, pero no de "inteligencia". Los animales son "listos", pero no "inteligentes" (de "intus-legere": leer dentro, interpretar la realidad). Tanto determinados animales como las computadoras pueden realizar mejor que los seres humanos determinadas funciones mecánicas o sensoriales. Pero sólo el ser humano comprende y es consciente de lo que hace en una medida en que difícilmente podemos atribuirles ni a los animales ni a las computadoras.

Resulta esclarecedora la fórmula que Zubiri utiliza para distinguir al mundo animal del humano. Para él es evidente que no se trata de una diferencia meramente cuantitativa sino cualitativa: la diferencia está en la forma de habérselas (habitud) con la realidad. Mientras a los animales la realidad se les da o se les actualiza como un conjunto de estímulos (formalidad de cstimulidad), al ser humano se le da bajo la formalidad de realidad, o de reidad ${ }^{\lceil 2}$. Esto implica una diferencia radical y cualitativamente distinta, que no consiste en una mera diferencia de cantidad de información percibida acerca de la realidad por el ser humano y por los animales, sino por situarse los primeros frente a un horizonte de comprensión de sí y de su mundo total y radicalmente diferente.

Según esto, los animales se acercan de alguna manera a los márgenes de la racionalidad humana, en la medida en que son capaces de manejar su entorno con habilidad, transmitir determinados mensajes, tener algún cierto atisbo de su mismidad, pero eso no resiste ninguna comparación serie con el mundo de los humanos.

Lo que constituye y configura el mundo de los humanos no es su extraordinaria habilidad técnica para dominar la realidad, sino, sobre todo, la capacidad de preguntarse por el sentido de su vida, de los demás, y del conjunto de lo que existe. Y junto a ello, su condición de ser un animal estético, ético y religioso. En el apartado siguiente me detendré en el aspecto de la ética, por lo que no me voy a extender más aquí al respecto.

51. Cfr. J. Ruffié, De la biologia a la cultura, Barcclona. Muchnik Editores, 1982.

52. Cfr. X. Zubiri, Inteligencia sentiente, tres vols., Madrid, Alianza/Fundación X. Zubiri, 1980-83. 
Sc suele acusar a las posturas humanistas antropocéntricas de especieís $m o^{5.5}$. Pero la clefinición que suele darse de este concepto es ambigua e incorrecta. Se clcline como especieismo a la postura que considera a los seres humanos cualitativamente diferentes al resto de especies animales, simplemente por el hecho de pertenecer a especies distintas. Es posible que haya quien defienda esta especie cle etnocentrismo especílico a favor de los humanos, pero no todo el que defien(le el salto cualitativo entre hombres y animales lo hace por la única razón de que son especies dilerentes, sin más. Los humanismos tratan de aportar razones supuestamente "objetivas" para justificar ese salto cualitativo. Otra cosa es que convenzan a toclos con sus razones. Lo que quiero señalar es que las definicioncs cle especicísmo que utilizan Singer, $\mathrm{P}$. Cohen y otros ${ }^{5_{4}}$ presuponen una actitud "clecisionista" en sus defensores, dando por hecho que no aportan razones objetivas (no sólo no convincentes) para defender esa postura.

Las razones que resultan más convincentes para defender la diferencia cualilativa entre hombres y animales están centradas en estos cuatro campos, algunos cle los cuales ya los hemos señalado algo más arriba:

- La diferente estructura comportamental. Mientras los animales tienen daclas sus formas de comportarse (el conjunto de pautas de conducta, o "elograma", según Lorenz) por transmisión genética, los seres humanos nacen, desde este punto de vista, como "animales deficientes" (Mängelwesen, A. Gehlen ${ }^{55}$ ): la naturalcza no les da pautas seguras de comportamiento, sino que tienen que decidir entre varias posibilidades de acción, siendo esta "deficiencia" la base biológica de la libertad y de su capacidad ética. Esto no quiere decir que los animales superiores no hayan superado un estilo de conducta instintivo; por supuesto que sí, pero su estructura comportamental es idéntica para toda la especie, y no pueden salir de ahí. Afirmar otra cosa sería tanto como dotar a ciertos animales de libertad, y por tanto de responsabilidad, cosa que de momento no se atreven a hacerlo los partidarios de la "liberación animal";

-El diferente modo de habérselas con la realidad: es el planteamiento de Zubiri señalado más arriba. Los animales perciben sólo estímulos; los seres humanos, realidades. Sólo si se reflexiona con detenimiento lo que implica la

5.3. La palabra inglesa speciesism se empezó a traducir por algunos como "especismo" (por cj.. en la traducción de "Liberación animal", de Peter Singer), pero parece más correcto y se está imponiendo de forma general traducirla como "especieísmo".

54. Peter Singer define del siguiente modo el "especieísmo": "El especismo (la plabra no es atractiva, pero no se me ocurre otra mejor) es un prejuicio o actitud parcial favorahle a los intereses de los miembros de nuestra especie y en contra de los de otras": "Liberación animal", o.c., p. 42. En este mismo lugar, en nota al pie de página, Singer señala que este término speciesism lo utilizó por primer vez Richard Ryder. Cti. también P. Cohen, Una concepción inherentista de los animales, o.c.

55. Cli. A. Gehlen. El hombre, Salamanca, Sígueme, 1980. 
idea de realidad - como horizonte transcendental en el que se sitúa la vida del ser humano- se podrá percibir y aceptar la radical diferencia de la condición humana respecto a los inimales;

- La capacidad de los seres humanos de estar abiertos al ámbito de la estética y de la religión. Ningún animal es capaz de abrirse a las calcgorías de helleza/lealdad. ni timpoco de abrirse a la estera de lo infinito y de lo trascenclente, siendo en cambio cstos ámbitos, junto con la ética, elementos constitutivos de la realidad humana;

- La capacidad de poder y de tener que elegir entre diversas posibilidades de actuar. optando libremente por una de ellas. y responsabilizándose ante sí mismo y ante los clemás de sus diferentes opciones.

Si csios elementos no constituyen razones suficientes para considerar razonable la postura humanistil, entendemos que se debe a la luerza de los ciprioris y prejuicios (en el senticlo neutro del término) desde los que parte la postura contraria. La reflexión epistemológica acerca de lo humano nos señala que nos acercamos sicmpre a los clatos de la realidad desde un horizonte de comprensión, constiluido por una visión ya previa del ser humano, un modelo de sociedad y un modelo de alrontar la cuestión sobre la trascendencia. Y sólo desde ese horizonte son aceptables o rechazables determinados datos cientílicos. Para no caer en una postura dogmática y lïdeísta, se necesita estar continuamente reajustando nuesrra propia relación dialéclica entre los datos de las ciencias y nuestra interpretación fiilosófico-cosmovisional ${ }^{5 h}$.

La postura de Singer y de sus seguidores es cleudora de un planteamicnto lilosólico que trata de entender al ser humano. como al resto de los animales, descle el horizonte de un darwinismo reductivo. Signilica que, cuando se estudia cualquicr especic animal. es eviclente que tanto su mortología como su comporlamiento son deudores de su herencia genética. De ahí que toda su vida se pueda entencler dentro del paradigma de la selección natural: tanto su conformación morlológica como sus estrategias conductuales están al servicio de la supervivencia y cle la transmisión de sus genes a la generación siguiente. El error está en querer comprender lo humano con este mismo esquema cerrado. Singer no cae en un biologismo reduccionista, ni tampoco pretende deducir la conducta humana desde sus bases genéticas. al estilo de los sociobiólogos más recalcitrantes. También tiene sumo interés, lo hemos visto con sus palabras, de evitar la "lalacia naturalista", pero advertimos en él una incorrecta conjugación, dentro de la realidad humana, de la dimensión biológica y la cultural, y, como conse-

56. Cli. sobre los presupucstos para conjugar los dilerentes modelos antropológicos y los clatos cientílicos sobre cl ser humano, C. Beorlegui. Antropología filosófíca. Nosotros: urdimbre solidaria y responsable. o.c.: J. M. Mardones, El retorno del mito. Madrid. Ed. Síntesis, 200(), cap. $7^{\circ}$.

¿Hacia un humanismo trans-antropocéntrico? 
cuencia de ello, una insuficiente valoración de la dimensión cultural, que le lleva a no ver en ella suficientes aspectos y motivos como para situar al ser humano en un nivel cualitativamente superior a cualquier otra especie animal.

Entendemos que la especie humana es una síntesis entre biología y cultura, dentro de la cual la biología es condición de posibilidad de la cultura, pero no su conductora. Una vez que emerge la cultura desde la biología, aquélla posee su propio dinamismo interno, puesto que persigue fines autónomos respecto a lo biológico ${ }^{57}$. El scr humano es la única especie que ha emergido y se ha autonomizado (no independizado) del mundo de la biología, cosa que no han hecho ninguna de las cspecies anteriores. De ahí que cuando se habla cle la vida humana y de la ricla animal, tenemos que ser conscientes que estamos hablando de conceptos analógicos. La linalidad de la "vida humana" va más allá de la mera supervivencia, porquc persigue fines éticos, estéticos, sociales, filosólicos, religiosos, elc., que, aunçue no pueden ir contra su base biológica, están más allá de ella. Incluso hay veces en que cl ser humano puede percibir su "vida" biológica como inaceptable porque la siente y experimenta (puede que equivocadamente) en contradicción con otros valores de nivel superior. "No vale la pena vivir así", pensamos a veces, en determinadas condiciones.

El ser humano, según esto, está abierto a este horizonte de vida (puede ser una buena traducción de la "formalidad de realidad" zubiriana) al que no llega, ni de lejos, ningún animal. Por tanto, la diferencia no es meramente de grado o de cantidad, sino cle cualidad. Estamos hablando de dos tipos de vida radical y cualitativamente distintas, por lo cue se puede concluir sin ninguna duda que los scres humanos. aun sin dejar cle ser animales, lo somos de modo cualitativamente dilerente ${ }^{\varsigma x}$. Puede verse que para ello no necesitamos echar mano de una lundamentación religiosa o "creacionista" del ser humano. Esta postura coincide con los planteamientos de cualquier humanista no creyente ${ }^{54}$.

Se suele argumentar para rebatir este salto cualitativo, que apenas hay diferencials genćticas y biológicas entre la especie humana y las que se hallan más cercanas en el proccso evolutivo, por ejemplo, los grandes simios. Pero eso no hacc más que confïmar un hecho admirable: la naluralcza innova poco, y con pocos cambios en lo genético puede dar lugar a especies con estilos de vida que

57. Para una correcta conjugación de lo biológico y lo cultural en el ser humano, cir. F.J. Ayala y Th. Dobzhansky (eds.). Estudios sobre filosofía de la biologia. Barcclona. Aricl. 1983: F. J. Ayala, Origen y erolución del hombre, o.c.; J. Ruffié, De la biolosia a la cultura, o.c.; R. Lewontin. La diversidad humana. o.c.

58. Cir. I. Ellacuría. Fundamentación biológica de la érica. ECA (Estudios Centroamericanos), 368 (1979), 418-428; Id.. Biologia e inteligencia, Realitas III-IV. Madrid. 1979, 29-157.

59. Orra cosa es que desde posturas creyentes resulte problemática la lundamentación última de un humanismo no creyente. Pero eso es un problema colateral. sobre el que habría mucho que discutir. 
poseen cambios sustanciales en lo fenotípico y en lo conductual ${ }^{60}$. Lo específico y lo diferente de la especie humana no está en poseer sustancias bioquímicas específicas, sino en estar estructurada su composición genética de forma diferente. Y eso lo sitúa en otra dimensión. Se ha dado, por tanto, en la aparición de lo humano, un salto cualitativo similar al que, como indica F. J. Ayala", se ha dado entre la no-vida y la vida, la vida unicelular y la pluricelular, o la diferencia de estado del agua por debajo y por encima de los $100^{\circ} \mathrm{C}$ de temperatura. Esos saltos cualitativos se advierten a posteriori, sin poder preverlos con anterioridad a que se den en el proceso evolutivo. Y tampoco podemos hacer otra cosa que constatarlo y explicarlo (erklären) científicamente, pero a la hora de comprenderlo (verstehen) en toda su significación metafísica y de sentido nos encontrarcmos con una multitud de propuestas ${ }^{\text {} 2}$.

En resumen, en la realidad humana el salto cualitativo se debe a su nueva y especial organización de lo biológico, a su nueva y especílica estructuración. Es la tesis cle Zubiri, cuando define lo psíquico como "la estructura dinámica de la rcalidad humana" ${ }^{63}$. Desde otro punto de vista, es la tesis también de la consideración del ser humano como "ser deficiente" de A. Gehlen, Portmann y otros"th.

\subsection{Un incorrecto planteamiento ético}

Este apartado está directamente apoyado en el modelo antropológico sobre el que hemos hablado en cl apartado anterior. Los modelos éticos son subsidiarios de sus correspondientes modelos antropológicos. La postura de Singer de luchar por equilibrar los derechos de ciertos animales con los seres humanos, hablando de esos animales como "personas" y pretendiendo que hay que concederles derechos "humanos", es consecuente con su postura sobre la no diferencia ontológica entre hombres y animales. En ese sentido, con las argumentaciones anteriores sería suliciente para zanjar esta cuestión. Pero entiendo que Singer comete lambién una serie de equivocaciones en sus planteamientos éticos que conviene aclarar.

Para Singer es incontestable que determinados animales (los grandes simios) son dignos de ser considerados como sujetos éticos, como personas, en la medicla en que poseen una racionalidad y sensibilidad suficiente, superior incluso a la

(6). Esia idea la repitc constantemente J. Ruffié en De la biologia a la cultura, o.c.

61. Clir. Origen y erolución humana. o.c.

62. Para la ya conocida polémica entre "explicación" y "comprensión". cfi. J.M. Mardones, Filosofía de las ciencias humanas y sociales. Materiales para una fundamentación cientifica. Barcelona. Anthropos, 1991; C. Beorlegui. Antropología filosófica. o.c.. cap. 2".

63. Clir. X. Zubiri. Sobre el hombre. Madrid, Alianza/Fundación X. Zubiri, 1986: Id.. LI hombre y Dios. Madrid. 1984; Id.. Estructura dinámica de la realidad. Madrid, 1989.

64. C.Ii. A.Gehlen, El hombre o.c.; A. Portmann (ed.). Um das Menschenbild. Stutgart. Reclam. 1964: Id. (ed.). Sinn und Wandlungen des Menschenbilden. Zürich, Rhein Verlag. 1972.

¿Hacia un humanismo trans-antropocéntrico? 
que poseen determinados colectivos humanos (niños pequeños y deficientes mentales), a los que la ética humana considera dignos de respeto y poseedores de derechos. Ya hemos contraargumentado antes desde la vertiente antropológica, y ahora lo vamos a hacer desde la ética.

Para no malinterpretar el mundo de la ética y considerarla en su auténtica realidad, tenemos que realizar algunas precisiones. Una distinción que resulta muy importante en este campo es la consistente en separar y distinguir entre capacidad ética y contenidos morales (o códigos éticos), tal y como lo hace Francisco J. Ayala ${ }^{\mathrm{A5}}$. Se trata de una distinción similar a la que realizó J. L. Aranguren entre ética como estructura y ética como contenido ${ }^{\text {th }}$. La capacidad ética, o ética como estructura, hace referencia al hecho de que la especie humana es capaz de realizar diferentes tipos de acciones y juzgarlas, según su código ético (que puede no ser el mismo para todos los seres humanos), como buenas o malas.

Esta capacidad la tiene el ser humano por su herencia genética; esto es, pertenece a su naturaleza. Su estructura genética le hace poseedor de las tres propiedades que Francisco J. Ayala considera como posibilitadores de esa capacidad moral: advertir la correlación causa-efecto entre las acciones, capacidad para distinguir entre valores, entre el bien y el mal, y tener libertad para elegir entre varias posibilidades de acción. Estas propiedades, posibilitadoras de la capacidad moral, sólo advertimos que las poseen los seres humanos, y en ninguna otra especie se dan.

Otra cosa diferente son los contenidos o los códigos morales, que pertenecen al ámbito cultural, y no depender directamente de lo biológico. En este aspecto, advertimos una evolución en la conformación de estos contenidos morales, así como una gran variedad entre las diferentes cultura. No vamos a meternos aquí en la problemática que esto plantea, y en cómo escapar al relativismo moral que esta experiencia al parecer nos aboca.

La capacidad ética implica en el ser humano dos consecuencias importantes. En primer lugar, le supone la obligación de tener que elegir entre diversas posibilidades de acción, y elegir adecuadamente, según su conciencia formada, y eso implica que es responsable de todos sus actos. En el fondo, no hay actos neutros, sino que el ser humano tiene que responder del conjunto de sus acciones. Y tiene que responder, primero, ante sí mismo, puesto que con sus acciones se construye o destruye como persona, como ser humano. $\mathrm{Y}$ tiene que responder también ante los demás, en la medida en que todas las acciones humanas tienen una dimensión social, y edifican o destruyen la convivencia social. Y para los creyentes, también hay una responsabilidad ante Dios.

65. Cfr. Origen y evolución del hombre, o.c., cap. 7ª, La ética y la religión.

66. Cfr. José Luis L. Aranguren, Ética, Madrid, Rev. de Occidente, 1958. 
Pero, en segundo lugar, la capacidad ética implica que el ser humano, a diferencia de las demás especies animales, posee un valor y una dignidad especial, por estar enriquecida su realidad por esta cualidad fundamental. De ahí que afirmemos que el ser humano posee una dignidad y una densidad ética y ontológica que no posee nadie más que él en el ámbito intramundano.

Cuando Singer habla de "derechos humanos" ${ }^{\circ 7}$ de los animales está defendiendo incorrectamente determinadas obligaciones de los humanos hacia los animales, en función de un valor intrínseco (que está inevitablemente de fondo de su teoría consecuencialista) que supuestamente poseerían esos animales. Pero esa exigencia no es convincente, porque Singer no demuestra nada. Otra cosa es que se pida a los humanos que no torturen, ni maltraten a los animales, y que les traten con una cierta dignidad y respeto. Pero entiendo que no es necesario para defender ciertos derechos de los animales considerarlos poseedores de una dignidad similar a los seres humanos y atribuirles el carácter de "persona".

Por todo esto, hay que distinguir, a la hora de hablar de "sujeto ético" como merecedor de derechos, de un sujeto "activo" y un sujeto "pasivo". El sujeto "aclivo" sería quien posee lo que hemos llamado "capacidad ética" (ética como "estructura"), que le dota de libertad y de responsabilidad. De tal manera que no sólo tiene derechos sino también obligaciones. Entre sujetos activos de derecho, se da una reciprocidad transitiva, dentro de la cual han nacido precisamente los derechos, como un mecanismo con el que limitar mis intereses frente a los intereses de los demás. Así, yo tengo defendidos mis derechos frente a los otros sujetos, y mi obligación está en no conculcar los derechos de los demás sujetos.

En ese sentido, en cuanto tengo obligación de no conculcar los derechos de los demás, soy sujeto activo. En cuanto que tengo derecho a que los demás respeten mis intereses, soy sujeto pasivo. Ahora bien, esta capacidad de sujeto

67. Siempre me ha resultado curioso, y contradiciorio con el conjunto de su planteamienIo, la aplicación del adjetivo "humano" a los supuestos derechos de los animales. Sería aceptable si con ello se quisiera reivindicar para los animales (o sólo para algún grupo determinado de ellos) algunos de los derechos de los seres humanos, en función de tener compasión hacia determinadas situaciones de crueldad humana hacia ellos. Pero lo que no resulta convincente es justificar esta petición atribuyéndoles a los animales determinadas cualidades (en este caso, poder sufrir y gozar) que supuestamente les igualarían a los seres humanos. Es cierto que Singer señala que no le interesa tanto defender la igualdad de hombres y animales, sino defender los derechos de éstos, derechos a no padecer sufrimientos causados por los humanos (cfr. Liberación animal, o.c., p. 44). Pero el problema está cuando entran en conflicto un bien o un sufrimiento animal y un humano. Para el humanista antropocéntrico está claro que. la obligación moral está en preferir el bien y evitar el mal del ser humano antes que cl del animal no humano, cosa que no quedaría siempre clara para Singer y sus partidarios.

¿Hacio un humanismo trans-antropocéntrico? 
pasivo está íntimamente relacionada con la dimensión de sujeto activo, puesto que esa dimensión es la que nos da a los humanos la entidad y valía ética suficiente como para exigir que se respeten nuestros derechos, esto es, nuestra dimensión de sujetos pasivos.

En el caso de Singer, no parece advertirse la íntima relación entre ambas dimensiones, en la medida en que está exigiendo derechos para ciertos animales, pero sin presuponer que posean capacidad de ser sujetos éticos activos, capacidad de responsabilidad. Entendemos que este punto nos muestra en qué medida hay una carencia de fundamentación suficiente en su planteamiento, puesto que nadie es digno de poseer determinados derechos si no se justifica una cierta dignidad o capacidad, como sí ocurre en los seres humanos.

Ante estas argumentaciones, Singer se defienden indicando que también en determinados colectivos humanos (niños y deficientes mentales) se hallan separados su condición de poseer derechos sin poder exigirles obligaciones. Y, por tanto, lo mismo tendríamos que pensar de los simios: a pesar de que no podemos exigirles responsabilidades por acciones violentas con sus semejantes o con los humanos ${ }^{1 \mathrm{ik}}$, siguen siendo sujetos de derechos. No es mala argumentación, pcro posee una grave deficiencia. Mientras que a los niños y a los deficientes mentales los consideramos una excepción respecto a la normalidad humana (a los primeros, porque todavía no han adquirido dicha normalidad; y a los segundos. porque un accidente en su desarrollo ontogenético les ha privado para siempre de alcanzar csa normalidad), en el caso de los simios estamos hablando de su lorma peculiar de ser, de su condición natural. Y esa condición natural no cstá dotada de los ingredientes específicos, entre ellos la capacidad ética, como para atribuirles lo que llamamos personalidad, dignidad humana, etc. Otra cosa distinta es que debamos tenerles consideración, no hacerles sufirir indebidamentc y cstablecer una normativa que legisle el comportamiento humano hacia ellos. Creo que es lcgítimo trabajar en esa dirección y delender determinados "derechos" de los animales. Pero no creo que eso pueda hacerse apoyándose en una supuesta igualdad ética entre animales humanos y no humanos.

En definitiva, nos hallamos ante dos actitudes muy diferentes respecto a los derechos de los animales:

a) La de quienes entienden que reclamar tales derechos supone desechar la dilerencia ontológica con respecto a los seres humanos y propugnar la atrihución para los mismos de la calegoría de "persona" y de "sujeto ético",

b) Y la de quienes defienden la necesidad de acomeler una legislación cue protcja a detcrminados animales del maltrato que algunos scres humanos les

68. Clir. Ia entrevista a Peter Singer realizada por Javicr Sampedro, El País (Madrid). 26 dc abril de 1999. p. 35. 
ocasionan. Pero entendemos que no se necesita, para apoyar esta postura, apclar a ningún tipo de defensa de la igualdad ontológica y ética entre hombres y animalcs.

Aquí no nos vamos a detener en discutir cuáles serían las orientaciones para csal legisiación en defensa de los animales ${ }^{(1)}$. Pero sí es importante señalar que lal legislación no podrá soslayar muchos momentos en los que se hallará ante conllictos de intereses entre los humanos y los animales. En tales casos, enten(lemos que el antropocentrismo ético es legítimo e inevitable, y que los derechos de los scres humanos tendrán que pasar por delante de los de los animales.

Un aspecto de interés, pero también lleno de ambigüedad, es la orientación (lc Singer de situar el punto de arranque de la ética y el criterio de diferenciación cntre lo ético y lo no ético en el ámbito del sentimiento y de la sensibilidad. Ya hemos visto que, siguiendo a Bentham, sitúa la capacidad de sentir, de suf rir y de gozar como elemento clave para discriminar entre seres éticos y quienes no Io $\operatorname{son}^{71}$. El que puede sufrir y gozar es susceptible de poseer intereses que defender para desarrollar su vida. Y esos intereses se defienden a través de los "derechos" que pueden exigir a los demás.

Hoy día diversas corrientes éticas de gran interés, como la ética de la liberación o la élica del rostro (Lévinas, y en general, toda la sensibilidad ética judía), insisten en que es la compasión ante el dolor ajeno la luente de la ética, y no lanıo la rellexión abstracta sobre la defensa del equilibrio de los derechos indivicluales. Por tanto, es la sensibilidad y no la razón la fuente que empuja a confeccionar una ćlica que evite el dolor ajeno y la injusticia. De ahí también la insistencia en el Ilamado por Dussel y por Hinkelammert el "principio material" de la ética, completado luego por el "principio formal" de la racionalidad comunicativa ${ }^{71}$.

Pero el problema está en que la compasión ética se entiende y se vive de dilerente modo si se orienta hacia un ser humano que hacia quien no lo es. Y no por capricho, como parecen indicar los que tachan esta postura de "especieísmo", sino porque se entiende que un ser humano es cualitativamente más valioso que cualquier animal, por más valor que se le quiera atribuir a éste último. El dolor

69. Cfi. Ios textos de Peter Singer, Liberación animal y El proyecto "gran simio", así como el de Mosterín. ;Vivan los animales! y el de Mosterín y J. Riechmann, Animales. y ciucladanos, donde se dan suficientes orientaciones acerca de estas convenientes y necesarias normativas a implementarse.

70. Cfir. Peter Singer, Liberación animal, o.c., pp. 44-45. Es interesante recordar que también M. de Unamuno ponía el dolor, la capacidad de sufrir, como la categoría clave de la vida humana: cfr. Del sentimiento trágico de la vida. Madrid, EspasaCalpe. 1976.

71. Clit: E. Dussel, Ética de la liberación. Madrid, Trotta, 1998; C. Beorlegui, La nueva ćitica de la liberación de E. Dussel, Realidad, 1999, № 72, 689-730.

¿Haclo un humanlsmo trans-antropocéntrlco? 
de un scr humano y las injusticias de las que pueda ser objeto, se estarían ejercien(o) sobre alguien con una dignidad inconmensurable, un lin en sí y nunca un medio para nada ni para nadie. Por tanto, vemos que una correcta articulación de la normativa ćlica exige tener claros los principios antropológicos, que nos piden una dilerenciación cualitativa entre hombres y animales, o, si sc quiere, entre "animales" humanos y no humanos.

La supuesta valía proyectada sobre Ios animales que determinados autores hacen gala en sus escritos, no es más que un comprensible antropomorfismo, que quiere ver en los animales la proyección afectiva y sensible que han puesto cn esos seres tan maravillosos que son los animales, y que algunos llevan a cxageraciones peligrosas en el caso de sus mascolas más cercanas. No es que queramos satanizar la sensibilidad creciente hoy día hacia los animales de companía. Ni tampoco nos parecen baladíes las argumentaciones de determinados autores. en cl sentido de que la sensibilidad y compasión hacia los animales suele constituir un termómctro de sensibilidad humana y ética hacia los demás hombres. Y también es cierto que las sociedades que mejor cuidan a sus animaless suelen ser más civilizadas y quizás más democráticas. Pero también es cierto que resulta sospechoso que en ciertas sociedades. y en determinadas personas, scal malyor la sensibilidad hacia sus animales domésticos y de compañía que hacia sus hermanos de la misma especie, que desgraciadamente en cantidades vergonzosals, por lo excesivas, viven en condiciones materiales, psicológicas y sociales mucho peores que muchos animales, tanto domésticos como en estado natural.

Una muestra cle ello, pero podrían traerse a cuento otros muchos casos, y que como anćcdota vale lo que vale, está en el reciente caso, aparecido en la prensa, de una ciudadana danesa, Elisabeth Elfriede Christiansen, de ochenta y cinco ainos. yue ha donado su herencia (de 500 mil coronas, equivalente a 60 mil dólares) al morir a seis chimpancés del Zoo de Copenhague. La razón de tal generosidad es que acudía diariamente, con su hija, enferma mental, al zoo donde visitar a los simpáticos chimpancés constituía para ella y su hija un auténtico encuentro terapéutico. Uno se pregunta por qué no nos compadecemos más de tantos humanos que tienen muchas más necesidades, y cuya compañía nos haría posiblemente mayores efectos terapéuticos, existenciales y espirituales.

\subsection{Una simplista propuesta sociológica}

Hemos visto ya que Singer ha completado recientemente sus teorías éticoantropológicas con una propuesta sociológica, que denomina "izquierda darwiniana", y que tiene la pretensión de sustituir al marxismo como filosofía sostenedora de Ios alientos utópicos por construir una nueva sociedad, que deje atrás todo tipo de alienación y de sufrimiento.

Las razones con las que pretende enterrar al marxismo son tanto de tipo teórico como práctico. La experiencia de socialismo real llevada a cabo por los 
países socialistas del Este europeo, han mostrado, según Singer, que no puede llcvarse a cabo con éxito una propuesta de sociedad nueva y liberadora de los seres humanos basada en una errónea teoría sobre el ser humano, como es la que ticne el marxismo.

Y en este aspecto teórico es donde se va a centrar el ataque de Singer contra el marxismo. La discrepancia fundamental, como ya lo hemos visto con antelación, es su diferente modo de entender la naturaleza humana. Mientras el marxismo defiende la absoluta maleabilidad de la naturaleza humana, pretendiendo en consecuencia que se puede hacer de él lo que se quiera, dependiendo del entorno sociopolítico cjue se construya. Singer, con su propuesta de izquierda darwiniana, cntiende que hay una naturaleza biológica humana que no tiene que ser respetada y no es susceptible de malear de lorma indefinida. Para mostrar esta realidad, Singer, apoyándose en algunos etólogos y antropólogos culturales, aporta una serie de supuestas pruebas que muestran la universalidad de muchas costumbres culturales.

Entendemos, como juicio inicial, que la parte sociológica es la más débil y superficial del sistema teórico de Singer. Quizás haya que achacarlo a que es la parte más reciente y por ello menos trabajada de su obra. Es posible. Pero lambién, por eso mismo, es donde mejor aparecen las profundas insuficiencias y contradicciones de todo sus sistema teórico.

Es lácil estar de acuerdo con Singer a la hora de criticar las insuficiencias, tanto teóricas como prácticas, del marxismo. Pero a la hora de señalar sus insuliciencias teóricas hay que afinar más el análisis. Por ejemplo, los marxistas clelienden que el ser humano es maleable por el ambiente sociopolítico, pero no tanto que defiendan ingenuamente que se puede hacer del ser humano lo que se quiera. En ese sentido, ningún marxista significativo ha llegado afirmar desde su teoría lo que el conductista Watson afirmaba respecto a la absoluta maleabilidad del ser humano desde los condicionantes ambientales ${ }^{72}$.

Por otro lado, cuando el propio Singer nos quiere mostrar la condición biológica del ser humano, a lo único que llega es a decir que existen constantes conductuales en todas las culturas e individuos. Pero para que esa línea argumentativa fuera demoledora, tendría que mostrarse que toda la estructura conductual de todos los seres humanos está configurada por patrones genéticos y biológicos, teniéndose que suprimir, como consecuencia, el concepto de "cultura". Pero eso está muy lejos de poder probarse, aparte de que va contra la evidencia de nuestra vida ordinaria y el sentido común.

72. Sobre el conductismo, cfr. J.B. Watson, Behavior: An Introduction to Comparative P.sicholog.v, 1914; Id., Behaviorisin, 1925: B.F. Sckinner, Walden Two, 1948 (trad. cast.: Walden dos, 1971); Id.. Science and Human Behavior, 1953 (trad. cast.: Ciencia y conclucta humana. 1974).

¿Hacia un humanismo trans-antropocéntrico? 
La etología animal nos muestra que, aunque en las especies que han aparecido más recientemente en el proceso evolutivo ya no se da una conducta cerrada y sometida a parámetros instintivos, la conducla cle todos los individuos de la misma especie es similar. En cambio, en el ser humano, cada cultura tiene sus parámetros de comportamiento y de comprensión de la realidad dificrentes. El ser humano es animal cultural porque ha superado el constreñimiento de lo biológico, y no tiene más remedio que inventar su modo de reaccionar ante el cntorno ambiental. Y el resultado de tal invención es la pluralidad de las culturas. Presentar como prueba de la existencia de una naturaleza humana biológica la constatación de que vivimos en sociedades, que tales sociedades se organizan jerárquicamente, que nos preocupamos del bienestar de nuestros parientes, que hay tendencia a que hombres y mujeres desempeñen roles respectivos semejantes, etc..$^{73}$, es enormemente trivial y no prueba nada, porque todos esos rasgos y propiedades se concretan de forma muy distinta en cada cultura. Y esa constalación tan evidente sirve precisamente para sostener la postura contraria de la quc nos está proponiendo Singer.

Siguiendo las argumentaciones de Singer, uno advierte que lo que de londo nos quiere hacer ver es que el "ingenuo" (según Singer) planteamiento de marxistas y cristianos, que predican la solidaridad y el olvido de uno mismo para trabajar por un mundo basado en el altruismo y en el olvido de sí, va contra un elemental imperativo biológico: la búsqueda del propio interés. De ahí que eche mano de la Regla Cardinal de Garrett Hardin: "Nunca pedir a nadie que actúe contra sus propios intereses"74.

No cabe duda de que en este punto hay un elemento que no hay que menospreciar. El socialismo que se implantó en los países del Este europeo, olvidó demasiado al individuo y sus intereses privados, desde la libertad de conciencia hasta la propiedad privada y la posibilidad de promover sus propias empresas. Y no cabe duda de que ese olvido, entre otros factores, fue su tumba. Pero no podemos ser tan ingenuos que elevemos el propio interés a un elemento intocable de la naturaleza humana. Esto explica también cómo Singer se sitúa entre quienes echan mano de la "teoría de los juegos" y todas las teorías e investigaciones promovidas en su entorno para querer hacernos creer que la naturaleza biológica humana nos viene a mostrar que la vida social humana está configurada por un conjunto de estrategias encaminadas, desde la base del propio interés, a sacar el máximo provecho del mercado de egoístas en que parece que consiste la sociedad humana.

No vamos a negar ahora la radical tendencia egoísta de nuestra naturaleza humana. Pero lejos de convertir esa tendencia en algo definitivo y a respetar,

73. Cfr. Peter Singer, Una izquierda darwiniana, o.c., pp. 54-55.

74. Cfir. Ibídem, p. 59 y ss. 
parcce responder más a nuestra auténtica condición scr consciente de esa tendencia y tratar de orientarla y educarla hacia una coopcración basada en un real y progresivo altruismo. Esto lo puede decir quien está convencido de que el ser humano es un animal que ha surgido del proceso evolutivo, y sigue teniendo en su cstructura esencial genética almacenada toda la historia competitiva de la evolución. pero también es cierto, como contrapeso, que dentro de sus posibilidades abiertas está la de hacer una sociedad basada en la igualdad y en la solidaridad.

Dentro del ámbito de los saberes que se dedican al estudio de los comportamientos humanos. tanto desde el lado de la psicología como desde lo bio-gcnético, las posturas más razonables hace tiempo que han abandonado la polémica estéril que elegir entre sólo lo biológico o lo cultural como determinante de la conducta humana. Se trata de una dicotomía demasiado abstracta. La base de la estructura comportamental humana es la suma de lo genético y de lo ambiental, sin que sea lácil señalar la parte correspondiente a cada una de las dos vertientes.

Por tanto, no se puede hacer propuestas socialcs y políticas sin tener en cuenta los datos de la biología, pero tampoco se puede defender que la sociedad humana no será más que un mero desarrollo de las propiedades biológicas humanas. Tanto las personas como las sociedades humanas son el resultado de lo que los seres humanos han hecho, dentro de las muchas o pocas posibilidades ambientales. con sus potencialidades genćticas y biológicas.

Algunos comentaristas críticos de los planteamicntos de Singer y de sus sc guidores. como es el caso de Carlos Castrodezza ${ }^{75}$, silúan sus propuestas den(ro de una nueva sensibilidad y estrategia del ser humano por sobrevivir en el cntorno terráqueo en que ha sido implantado por el proceso evolutivo. Aunque no estemos de acuerdo con el marco global del planteamiento de Castrodezza, demasiado encerrado en un biologismo reductivo, nos resultan interesantes los análisis del trasfondo teórico en el que sitúa el empeño de Singer y sus defensores, desde la óptica de una nueva visión económica de la realidad humana. Para Castrodezza, esta nueva sensibilidad defensora de los derechos de los animales, desde la oposición a toda práctica de crueldad contra ellos, estaría en sintonía con una nueva teoría económica que pretende dejar obsoleta la economía clásica, vigente en Occidente desde A. Smith.

Tocla propuesta económica respondería, según Castrodezza, a una oplimización de los recursos naturales dentro de una estrategia de supervivencia. La economía clásica se basa en un planteamiento humanista antropocéntrico, considerando el cntorno ecológico como un amplio ámbito de recursos del que el ser humano tiene que nutrirse para sobrevivir. Así, pues, cada individuo tiene que trabajar

75. Clir. C. Castrodezza, Ética, economia y derechos de los animales en un marco naturalista, Teorema. XVIII/3 (1999), 117-135.

¿Hacia un humanismo trans-antropocéntrico? 
para extraer los recursos suficientes, confiando en que una "mano invisible" (A. Smith) cuidará por todos, haciendo que haya recursos para todos y el equilibrio vital se mantenga.

Pero esta visión "providencialista" de la economía y de la historia ha mostrado su falsedad, puesto que nos hallamos en un momento histórico en que se advierte claramente que este paradigma económico ha producido todo el deterioro ecológico y la puesta en peligro de la supervivencia de la especie y hasta de todo el planeta. Esta situación de alarma es la que habría hecho surgir nuevas sensibilidades y nuevas teorías, que en el terreno económico Castrodezza lo ejemplifica en las teorías del economista rumano Georgescu Roegen ${ }^{76}$. Para esta nueva economía, el entorno ecológico no es ni inconmensurable ni aislado de nosotros, sino que forma un todo vivo que comprende todas las especies vivas y la especie humana entre ellas. Ya no se acepta la visión providencialista de la economía anterior, porque se tiene bien presente que muchas especies animales desaparecieron por no haber sabido respetar los sabios equilibrios de la naturaleza. La especie humana está en una situación diferente porque es consciente de su situación en el entorno ecológico en el que la ha tocado vivir, pero esa consciencia se convierte en un arma de doble filo, ya que por un lado puede advertir con antelación los peligros y corregir su equivocado rumbo; pero también pucde exacerbar sus potencialidades tecnológicas, fruto de su desmesurada capacidad racional, y provocar la mayor catástrofe ecológica de la historia del planeta.

Resulta extraño para estos pensadores (y no sólo para ellos) la ccguera de la mayoría de la humanidad ante estos riesgos tan evidentes, no quedando al parecer otra hipótesis explicativa que apelar a la irracionalidad humana, tal y como lo hace Stuart Sutherland ${ }^{77}$. Esta tendencia irracional ha dejado ciega a la humanidad ante el desastre y su propia destrucción que se avecina, sin importarle la responsabilidad de dejar o no a la próxima generación un habitat sano y capaz de seguir siendo una adecuada vivienda para el ser humano.

Toda teoría económica lleva consigo su propia concepción ética. Si la economía clásica proyectaba una ética del "individualismo posesivo", que parte de una concepción individualista y competitiva del ser humano, siendo la sociedad el resultado de un contrato de egoístas, contrato en el que no se tiene en cuenta cl entorno ecológico, esta nueva economía implica una visión integrada del ser humano dentro del entorno natural, que se convierte en el objeto de su preocupación no sólo porque sabe que si no lo cuida adecuadamente puede su deterioro suponer la muerte y la destrucción de la propia especie humana, sino porque para esta mentalidad la realidad natural está impregnada de un valor y dignidad

76. Cfi. G. Roegen, La Ley de la entropia y' el proceso económico. Madrid, Visor, 1996 (texto original: 1971).

77. Clir. S. Sutherland, Irracionalidad (El enemigo interior), Madrid. Alianza, 1996 (texto original: 1992). 
que equivale al valor del propio ser humano. Como puede verse, la consecuencia de esta visión global e integradora del planeta implica para ellos la disolución de la distinción cualitativa entre la especie humana y el resto de las realidades vivas y naturales. El ser humano es una realidad más en medio de todo el conjunto, y no se ve por qué se le tiene que primar con un especial estatus ético y/u ontológico.

Para Carlos Castrodezza, esta nueva sensibilidad que se va extendiendo en estos últimos años, es una nueva y adecuada estrategia que la especie humana, consciente de su situación, está desarrollando como modo más correcto de cumplir con la ley de "lucha por la vida" en la que estamos inmersos como todas las demás especies vivas. Se trata, pues, de un nuevo paradigma, que aunque presenta diversas formas de entenderse y de concretarse, responde, según el autor, a un mismo empeño de supervivencia en la nueva situación histórica en la que halla empeñada la humanidad.

\section{A modo de conclusión}

En la segunda parte de estas reflexiones, hemos ido presentando lo que consideramos son los puntos débiles de las propuestas de Peter Singer, por lo que ahora queremos of recer, de modo sintético y esquemático, las conclusiones que podríamos sacar de todo lo anterior.

1) En primer lugar, los planteamientos de la corriente de "liberación animal" o dclensora de los "derechos de los animales", cuyo representante más significalivo es Peler Singer, representa un síntoma de un nuevo modo de percibirse la humanidad en el entorno de su hábitat natural. Este modo de consciencia de lo humano exige paria esta leoría un replanteamiento de la propia concepción que cl ser humano tiene de sí mismo, así como una reconfiguración de la ética, de la sociología. de la economía, y de todos los saberes que conliguran la cosmovisión dominante de las culturas humanas. Podríamos decir que, al estilo de lo que el lundador de la "sociohiología", E. O. Wilson, proponía no hace muchos años ${ }^{7 k}$, sc necesitaría una "nueva síntesis" de pensamiento para dar cuenta de la nueva siluación en la que se encuentra el ser humano en el entorno planetario.

En lo que ticne de síntoma y en lo que supone de llamada de atención de esa nucva etapa o situación en la que el ser humano se encuentra, es meritorio y accrtado. No cabe duda de que, como señala M. Serres, la humanidad tiene que reoricntar la comprensión de su vida desde la fórmula de "contrato social" a la de "contrato natural". Otra cosa es que estemos de acuerdo en los contenidos de cse "contrato natural".

2) El punto clave de esta nueva cosmovisión, que constituye a su vez el punto central de nuestro desacuerdo, es la visión que propone del ser humano. Si resulta

78. Cli. E.O. Wilson. Sociobiologia. La nueva sintesis. Barcelona. Omega, 1980 (texto original: 1975).

¿Hacla un humanismo trans-antropocéntillco? 
positivo e inevitable situar al ser humano como un animal más del conjunto de la biosfera, de donde ha emergido por evolución y donde sigue anclado para su propia supervivencia, supone un error deducir de ello la necesidad de disolver la distancia cualitativa entre el ser humano y el resto de las especies vivas. Si no salimos de un punto de vista meramente biologista reductivo, parece que resulta comprensible entender a la especie humana como una especie más, sólo que más compleja; pero tal complejidad, para este punto de vista, sólo sería cuantitativa. Ahora bien, ya hemos indicado en su momento que un análisis más cuidadoso de la realidad humana nos revela su radical distancia del resto de los seres vivos. sin necesidad de cchar mano para ello de apoyaturas teológicas, como pretenden los "creacionistas". En csc sentido, discrepamos de los que pretenden reducir este problema a dos únicas posturas extremas: la creacionista, que sitúa al ser humano al margen del proceso evolutivo y milagrosamente emergido de las manos de Dios, y la postura delendida por los que abogan por la igualación entre hombres y animales. El abanico de posturas intermedias, además de ser amplio, es el más liructífero, puesto que los datos de los diferentes saberes antropológicos no hacen más que apoyar el único humanismo que nos parece digno de tal nombre: el que advierte entre el ser humano y las demás realidades una distancia de grado, cualitativa. Dicho humanismo pucde perfectamente compaginarse con una visión religiosa del mundo, sin nccesidad de entender la acción de Dios como cualquiera de las demás realidades intramundanas (o "causas segundas", scgún los escolásticos), sino entendiéndolo en otro nivel, como fundamento metalísico de todo lo que hay.

3) Desde esta correcta comprensión de lo humano. la propuesta ética de Singer no pucde por menos que parecernos llena de ambigüedades. No nos resulta difícil coincidir en ciertas propuestas encaminadas a poner coto a determinadas actividades humanas que implican crueldad con algunos animales. El respeto a los animales. respeto amparado en una valoración global de todo el universo, debería obligarnos a los seres humanos a revisar nuestra relación con nuestro entorno, de jando de cntender la naturaleza como una mera reserva de recursos naturales para satisfacer nuestras necesidades y extraer beneficios dentro de la lógica del mercado cconómico, para pasar a otra postura más respetuosa de la realidad viva.

Esta revisión de comportamientos llevaría aparejados, de rebote. un replanıcamiento de los valores que impregnan el mundo de las relaciones económicas, una revalorización de las propias realidades naturales, y el aprendizaje de comportamientos de compasión, que tendría a su vez repercusiones positivas dentro del ámbito de las relaciones interhumanas. Pero nos resulta totalmente inaceptable la equiparación en dignidad ética entre hombres y grandes simios que nos propone Singer, simplemente porque las razones en las que se apoya son totalmente insuficicntes. No vemos razones serias para que tengamos que abdicar de un humanismo antropocéntrico, que no es un mero "especieísmo" infundamentado. sino la postura más coherente con el hecho de que los seres humanos poseen una densidad ontológica y ética que los sitúan en el centro de la realidad mundana. Pero ello no 
significa de ninguna manera que la especie humana tenga carta blanca para actuar ante esa realidad como un dueño despótico sino como su cuidador respetuoso. El ser humano forma parte de la biosfera y depende de ella, y no la puede tratar impunemente de forma despótica.

4) Si seguimos hablando de "naturaleza humana", tenemos que entenderla como una estructura abierta, consciente de sí y en progresiva realización de sí misma, como fruto de su libre ejercicio de "apropiación de realidades", en expresión de Zubiri. Por tanto, el ser humano es fruto de lo que su dimensión genética y biológica le aporta, pero también de lo que el entorno cultural le va configurando. De modo que cada individuo es el resultado particular de cómo cada sujeto humano va dando lorma a la dialéctica biología-cultura. De ahí que tenga razón Singer al del'ender que ninguna propuesta sociopolítica tiene que olvidar los presupuestos biológicos de la naturaleza humana, pero tampoco liene que olvidar que ese aspecto no es cerrado ni totalmente determinante, sino un conjunto de posibilidades que cada cultura y cada proyecto político tiene que concretar y cristalizar, en una clinámica histórica abierta, que depende de las libres decisiones de los humanos. Por tanto, ni cl ser humano es totalmentc plástico, ni tampoco es el resultado inevitable de unas características genéticas que actúan de forma determinística. Estos clos lactores son modelados libremente, con las limitaciones que se quiera, por la propia subjetividad. El ser humano es, por tanto, el resultado de la conjugación cle eslas tres dimensiones, sin que, como dice M. Horkhcimer, se pueda determinar (jué corresponde a cada una de ellas" ${ }^{71}$. Cada ser humano es el resultado de la conjugación de cultura. naturaleza e individualidad, sin que haya reglas lijas que marquen la pauta en cada momento para conjugar los tres factores. De ahí que las críticas de Singer al marxismo sean acertadas sólo en el aspecto, no trivial, de un cierto olviclo de la dimensión individual del ser humano. Pero aun en este punto lo hace clesde una concepción demasiado biologista del ser humano, como si fuera algo lijo y detcrminante la tendencia de todo ser humano a buscar su propio interés, y hubicral que mantener esa tendencia como algo que no se puede tocar. De esta forma. claro estí. cstaría justificando el supuesto mayor acierto del capitalismo a la hora de entender la naturaleza especílica del ser humano. Así, scgún Singer, auncue el capitalismo no sea perfecto. al menos parece que es más realista que cl marxismo a la hora de partir de la auténtica naturalczá clel ser humano: la búsqueda de su propio intcrés por encima de todo. Así que el marxismo habría caíclo víctima clc su ingenuidad. al olvidar esta tendencia fundamental del ser humano. y creer que es totalmentc maleable. de moclo que un tipo de sociedacl sin propiedad privada le cambiaría automáticamente y le haría olvidar esta tendencia.

5) Si en juiciamos las teorías cle Singer desde la óptica crítica de la sociología del conocimiento. y nos preguntamos a cuién sirven o pueden scrvir o beneliciar.

79. C.ir. M. Horkheimer, Observaciones sobre la Antropologia fillossofica. (1936), en Teerria critica. Bucnos Aires. Amorrortu. 1974, pp. 5()-75.

¿Hacia un humanismo trans-antropocéntrico? 
cstos planteamientos, se advierte claramente, como ya apuntamos con anterioridad, una peligrosa y sesgada sensibilidad, que en terminología marxista se solía denominalr "burguesa", tendente a tener mayor o similar compasión por los animales que por millones de seres humanos que viven en condiciones infrahumanas, peores que muchos animales. En amplios sectores de la opinión pública primermundista, se ha extendido una sensibilidad ecológica y defensora de los animales, que en muchos aspectos representa una visión incompleta y sesgada de la realidad humana en su globalidad. Porque resulta un síntoma peligroso e inhumano anclarse en la compasión hacia los animales, y hacer de esta misión militante el ideal de vida, cuando nos hallamos en un momento de la historia humana en el que contamos con un porcentaje mayor que nunca de pobreza y de violaciones de derechos fundamentales hacia los seres humanos. Y esta situación de desigualdad entre el tercio hegemónico de la humanidad y el resto no sólo no se va acortando sino que los datos nos indican que va aumentado progresivamente. La tarea urgente de luchar por construir un mundo más justo y solidario, en que todos los seres humanos disliruten de los medios necesarios para su realización como personas, no se construye con teorías que tratan de distraer nuestra compasión de tanto ser humano empobrecido, para orientarla hacia los pobres animales enjaulados en las granjas de ganadcrías intensivas. Es verdad que pueden compaginarse ambas luchas, pero sabiendo situarlas en escalores diferentes y bien jerarquizadas.

Una ecología correcta y que integre toda la problemática que la mundialización nos está planteando, no pasa por difuminar la especial dignidad del ser humano para extenderla a ciertas especies animales, sino que implica estudiar las estrechas relaciones que existen entre una economía depredadora del entorno ecológico a favor de intereses de minorías capitalistas y una política internacional que convierte a los países del Sur en la reserva y en el basurero de los del Norte. Y este modo crítico e integrador de entenderse una ecología liberadora, no puede separarse de su piedra angular que no es otro que defender la especial dignidad de cada ser humano, por encima de toda otra realidad no humana ${ }^{\text {BO }}$.

80. Para el modo como orienta la reflexión ecológica la filosofía de la liberación latinoamcricana, Cfr. Para cómo orientar la reflexión ecológica desde la filosofía de la liberación latinoamericana, cfr. Ingemar Hedström, El desafio ecológico, Pasos, 1990. $n^{\circ}$ 28. 17-23; Id.. Ecología y desarrollo en Latinoamérica, Pasos, 1991, n 36, 17-19; Id.. Desequilibrio natural y social: un mismo origen, Pasos, 1985, $n^{\circ} 2,19-20$; Id., Hacer ecoteología es estar contra los proyectos para una muerte prematura, Pasos, 1986, $n^{\circ} 4$, 11-16; L. Boff, Religión, justicia societaria y reencantamiento de la creación. Pasos, 1993, n²5, I-10; Id., Las tendencias de la ecología, Pasos, 1996, n 68, 1 9; Roy H. May, Apuntes para una teología de la tierra, Pasos, 1996, $n^{\circ} 63,24-32$; Id., La tierra en tiempos de globalización, Pasos, 1998, n 76, 21 -25; J. Francisco Gómez Hinojosa, ¿Está viva la naturaleza? Apuntes para una ecología liberadora, I, Pasos, 1990, $n^{\circ}$ 30, 7-18; 11, Pasos, 1991, n 38, 1-12; Yamandú Acosta, Una crítica antropocéntrica al antropocentrismo desde la perspectiva de una radicalidad social, Pasos, 1993, n 73, 1-5. 